\title{
Mesostructured Silica-Coated Magnetic Nanoparticles to Extract Six Opium Alkaloids in Poppy Seeds Prior to Ultra-High-Performance Liquid Chromatography-Tandem Mass Spectrometry Analysis
}

\author{
Gema Casado-Hidalgo, Damián Pérez-Quintanilla (D), Sonia Morante-Zarcero $\mathbb{D}^{D}$ and Isabel Sierra *
}

Citation: Casado-Hidalgo, G. Pérez-Quintanilla, D.; Morante-Zarcero, S.; Sierra, I. Mesostructured Silica-Coated Magnetic Nanoparticles to Extract Six Opium Alkaloids in Poppy Seeds Prior to Ultra-High-Performance Liquid Chromatography-Tandem Mass Spectrometry Analysis. Foods 2021, 10, 1587. https://doi.org/ $10.3390 /$ foods 10071587

Academic Editor: Shahab A. Shamsi

Received: 1 June 2021

Accepted: 6 July 2021

Published: 8 July 2021

Publisher's Note: MDPI stays neutral with regard to jurisdictional claims in published maps and institutional affiliations.

Copyright: (C) 2021 by the authors. Licensee MDPI, Basel, Switzerland. This article is an open access article distributed under the terms and conditions of the Creative Commons Attribution (CC BY) license (https:// creativecommons.org/licenses/by/ $4.0 /)$
Departamento de Tecnología Química y Ambiental, E.S.C.E.T., Universidad Rey Juan Carlos, C/Tulipán s/n, Móstoles, 28933 Madrid, Spain; gema.casado@urjc.es (G.C.-H.); damian.perez@urjc.es (D.P.-Q.); sonia.morante@urjc.es (S.M.-Z.)

* Correspondence: isabel.sierra@urjc.es; Tel.: +34-91-488-70-18; Fax: +34-91-488-81-43
Abstract: In recent years, health authorities have become increasingly concerned about preventing consumer exposure to opium alkaloids present in Papaver somniferum L. poppy seeds. In this study, a simple, rapid and efficient method has been optimised to determine all main opioids in poppy seeds (morphine, codeine, thebaine, papaverine, noscapine and oripavine) by UHPLCQqQ-MS/MS. For this purpose, solid-liquid extraction (SLE) of samples was optimised and six magnetic adsorbent materials with a core of $\mathrm{Fe}_{3} \mathrm{O}_{4}$ coated with amorphous and mesostructured silica, both functionalised with octadecyl-silane or octyl-silane were characterised and evaluated for magnetic solid-phase extraction (MSPE). The material with the best results was non-functionalised mesostructured silica and, with it, the MSPE procedure was optimised. This method was validated and used to quantify six opioids in 14 edible seed samples (eleven poppy seeds and three seed mixes). Considerable amounts were found $(1.5-249.0 \mathrm{mg} / \mathrm{kg}$ morphine, $<0.2 \mu \mathrm{g} / \mathrm{kg}-45.8 \mathrm{mg} / \mathrm{kg}$ codeine, $<2.4 \mu \mathrm{g} / \mathrm{kg}-136.2 \mathrm{mg} / \mathrm{kg}$ thebaine, $<0.2 \mu \mathrm{g} / \mathrm{kg}-27.1 \mathrm{mg} / \mathrm{kg}$ papaverine, $<0.2 \mu \mathrm{g} / \mathrm{kg}-108.7 \mathrm{mg} / \mathrm{kg}$ noscapine and $<240 \mu \mathrm{g} / \mathrm{kg}-33.4 \mathrm{mg} / \mathrm{kg}$ oripavine), exceeding maximum limits established in some EU countries and the reference level of morphine in the EU. Furthermore, in some commercial samples for human consumption, inadequate labelling was found because significant amounts of alkaloids were detected even though Papaver rhoeas L. seeds were declared on the product label.

Keywords: opium alkaloids; poppy seeds; Papaver somniferum; mesostructured silica; magnetic solid-phase extraction; liquid chromatography-tandem mass spectrometry

\section{Introduction}

The seeds of the opium poppy, Papaver somniferum L., are widely used in the preparation of food products such as bakery, buns, yoghurt, snacks or tea [1-3]. Although Papaver somniferum L. poppy seeds hardly contain any opium alkaloid, they can be contaminated with latex by poor harvesting practices or insect damage. The main opium alkaloids that may be present are morphine, codeine, papaverine, thebaine, noscapine and oripavine. However, most of the previously published studies have focused mainly on morphine and codeine, without paying attention to the other alkaloids for which concentrations may also be relatively high and of concern due to their possible high levels of toxicity [4]. In addition, another problem observed at the commercial level is that, in most cases, only the poppy seed is indicated on the label and the botanical name is not considered. This is an important aspect because Papaver rhoeas L. seeds (corn poppy seeds) do not contain any opium alkaloids unlike Papaver somniferum L. [5]. If food products are made from contaminated seeds, they may result in adverse health effects, especially in babies, infants, the elderly and people with severe health issues [6]. Moreover, their consumption can 
produce considerable amounts of opium alkaloids in biological samples such as blood, urine and oral fluid, which is enough to cause false positive drug abuse testing [7-10].

Nowadays, there is no harmonised European legislation on opium alkaloids in poppy seeds for food purposes and each country is carrying out different actions [4]. For example, only poppy seeds can be used in the production of bakery products in Belgium [11]. In Austria, a classification of varieties with low morphine content for food use has been established [12]. In Germany, a maximum limit of $4 \mathrm{mg} / \mathrm{kg}$ for morphine in poppy seed for use in food has been established and, in Hungary, limits of $30 \mathrm{mg} / \mathrm{kg}$ for morphine, $20 \mathrm{mg} / \mathrm{kg}$ for noscapine, $40 \mathrm{mg} / \mathrm{kg}$ for the sum of morphine and noscapine, $20 \mathrm{mg} / \mathrm{kg}$ for thebaine and $20 \mathrm{mg} / \mathrm{kg}$ for codeine are set [11]. Due to the absence of harmonised legislation among the EU Member States, a considerably high number of RASFF (Rapid Alert System for Food and Feed) health alerts have been generated in recent years [4]. For this reason, a reference level of $10 \mathrm{mg} / \mathrm{kg}$ morphine in poppy seeds for direct human consumption has been established in the EU. This level is not a maximum limit, but an agreement between EU Member States in November 2016 [13] until the Commission establishes that new risk management measures concerning the presence of opium alkaloids in food are necessary [5]. In addition, the European Food Safety Authority (EFSA) in 2011 carried out a risk assessment and established an acute reference dose (ARfD) of $10 \mu \mathrm{g}$ morphine/kg body weight (b.w). In 2014, the European Commission published a set of recommendations for good agricultural and seed processing practices to reduce the morphine content in poppy seeds [14]. In 2018, a new EFSA opinion was published and its main conclusion was that more studies are needed to determine the presence of the six main opium alkaloids in edible seeds available on the market to evaluate the real exposure of consumers to all of these toxins and to create a harmonised legislation [15].

In order to carry out these studies, it is necessary to develop methods in food matrices that are effective, simple and rapid. Some of these alkaloids are found at ultra-trace levels in very complex matrices. For this reason, a selective and sensitive analytical technique is required. The most commonly used is chromatography, such as gas chromatography-coupled mass spectrometry (GC-MS) [10,16]. However, the costly step of sample derivatising has resulted in the increased use of (ultra)high-performance liquid chromatography ((U)HPLC). Multiple detectors can be used, such as the diode array [17] or ultraviolet [18], but the preferred technique for analysis of opium alkaloids is (U)HPLC coupled to triple quadrupole mass spectrometry ((U)HPLC-QqQ-MS/MS) with multiple reaction monitoring (MRM). However, to avoid co-eluted endogenous matrix components and to reduce the matrix effect that can be produced in MS detection, it is very important to do an adequate sample treatment in order to minimise the possibility of false results. Traditional procedures that are commonly used include solid-liquid extraction (SLE) with organic solvents $[1,6]$ or solid-phase extraction (SPE) to perform sample purification $[19,20]$. The current trend in sample preparation involves the adoption of more automated, simple, fast and environmentally friendly approaches, mainly by integrating new adsorbent materials in the purification stage by means of microextraction techniques [4,21]. A powerful new purification alternative is solid-phase magnetic extraction (MSPE) that is faster and simpler. MSPE consists of dispersing the magnetic material in a solution with the sample for a few minutes. Once it is in equilibrium, it is recovered with the help of a magnetic field and, finally, the analytes are desorbed which can avoid tedious filtration, centrifugation or sedimentation steps [22]. Adsorbent material type is an important parameter in MSPE procedure because it will determine the ability to purify the samples. Until now, $\mathrm{Fe}_{3} \mathrm{O}_{4}$ particles covered with amorphous silica are the most used as a magnetic adsorbent, which can be functionalised with different organic groups as natural polymers or graphene [22-25]. However, the use of mesostructured silica is increasingly important because of their larger surface area, which can bind more of the functional groups and their uniform porous structure can facilitate access to the analytes [26,27]. However, MSPE procedures with this type of adsorbent material have not yet been developed to study all the main opium alkaloids present in poppy seeds. 
The aim of this work was to develop and validate a rapid, easy and efficient method to determine the six main opium alkaloids, morphine, codeine, thebaine, papaverine, noscapine and oripavine in poppy seeds by UHPLC-QqQ-MS/MS. For this purpose, a SLE-MSPE sample preparation protocol was optimised using mesostructured silica-coated magnetic nanoparticles as the adsorbent. The method was successfully applied for the quantification of the six opioids in eleven poppy seeds and three seed mixes available in national food supermarkets to evaluate the levels of these alkaloids in seeds destined for food consumption.

\section{Materials and Methods}

\subsection{Reagents and Materials}

Standards of morphine, codeine, thebaine and oripavine were received from Alcaliber S.A.U. (Madrid, Spain). Noscapine, papaverine and morphine-D3 (internal standard) were obtained from Sigma-Aldrich (Sigma-Aldrich, Zwijndrecht, The Netherlands). Individual stock standard solutions were prepared at $1000 \mu \mathrm{g} / \mathrm{mL}$ in methanol. The intermediate mixed standard solution was prepared at $10 \mu \mathrm{g} / \mathrm{mL}$ in methanol. The working standard solutions were prepared at $1 \mu \mathrm{g} / \mathrm{mL}$ by diluting the intermediate mixed standard in methanol/water 50/50 (v/v). All of these were stored in darkness at $-20^{\circ} \mathrm{C}$.

Ferric chloride 6-hydrate $\left(\mathrm{FeCl}_{3} 6 \mathrm{H}_{2} \mathrm{O}\right) 99 \%$ and ferrous chloride 4-hydrate $\left(\mathrm{FeCl}_{2}\right.$ $4 \mathrm{H}_{2} \mathrm{O}$ ) $99 \%$ were purchased from Labkem (Barcelona, Spain) and Acros Organics (Geel, Belgium), respectively. Tetraethylorthosilicate (TEOS) 98\%, hexadecyltrimethylammonium bromide (CTAB) 98\%, chloro(dimethyl)octylsilane $\left(\mathrm{C}_{8}\right)$ and chloro(dimethyl)octadecylsilane $\left(\mathrm{C}_{18}\right)$ were purchased from Sigma-Aldrich. HPLC grade acetonitrile, methanol and formic acid were purchased from Sigma-Aldrich. Ammonia (32\%,w/w), isopropanol, toluene, ethanol and diethyl ether were of synthesis grade and acquired from Scharlab (Barcelona, Spain). Ultrapure water (resistance $18.2 \mathrm{M} \Omega \mathrm{cm}$ ) was obtained from a Milli-Q water purification system (Millipore, Billerica, MA, USA). The Nd-Fe-B magnet $(5 \times 5 \times 2 \mathrm{~cm})$ with force $200 \mathrm{~kg}$ used in the MSPE procedure was obtained from Superimanes S.L. (Sevilla, Spain).

\subsection{Sample Collection}

At the end of 2020, 14 samples of edible seeds were purchased in Spain from some supermarkets and herbalists, out of which three are mixtures of different edible seeds (pumpkin, sunflower, sesame, gold flax, brown flax and poppy seeds). In addition, for comparative purposes, two wild samples, one of white opium poppy (Papaver somniferum L.) and the other of corn poppy (Papaver rhoeas L.) were collected in Madrid and Zaragoza, respectively. Detailed information on each of these samples can be found in Table S1.

\subsection{Synthesis of Organic-Functionalised Magnetic Particles}

Magnetic particles $\left(\mathrm{Fe}_{3} \mathrm{O}_{4}\right)$ were coated in a first step with amorphous silica $\left(\mathrm{Fe}_{3} \mathrm{O}_{4} @ \mathrm{SiO}_{2}\right)$ and, after, with mesostructured silica $\left(\mathrm{Fe}_{3} \mathrm{O}_{4} @ \mathrm{SiO}_{2} @ \mathrm{mSiO}_{2}\right)$. In addition, both materials were functionalised with organic groups $\left(\mathrm{C}_{8}\right.$ or $\mathrm{C}_{18}$ ligand). The schematic preparation process of different magnetic particles is shown in Figure 1a. 
(a)

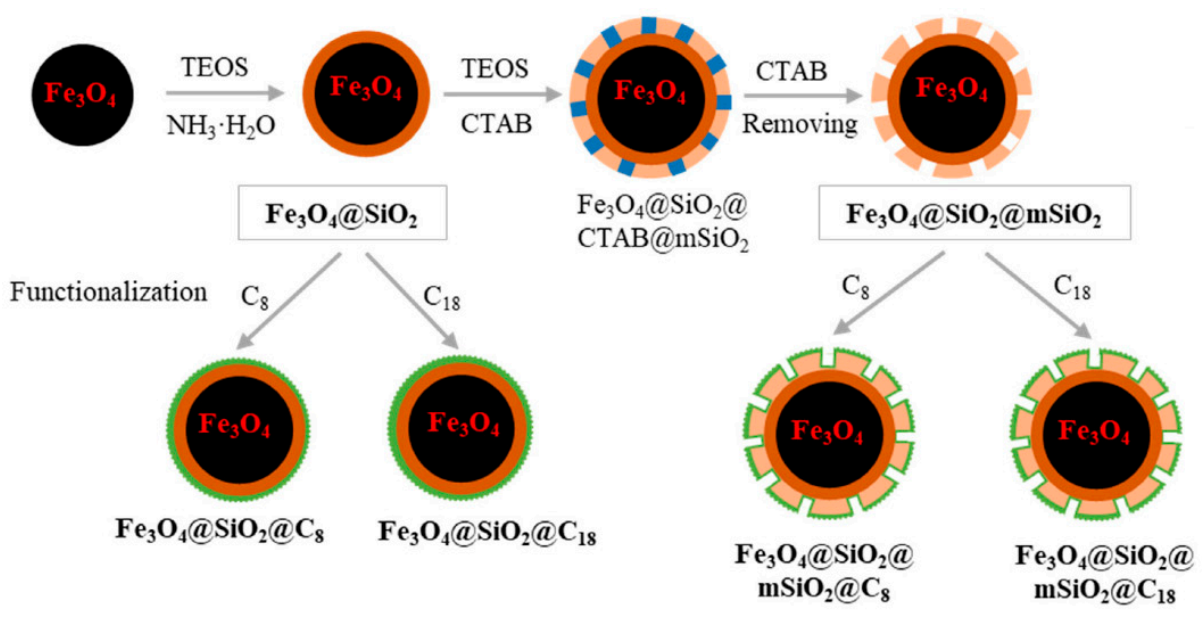

(b)
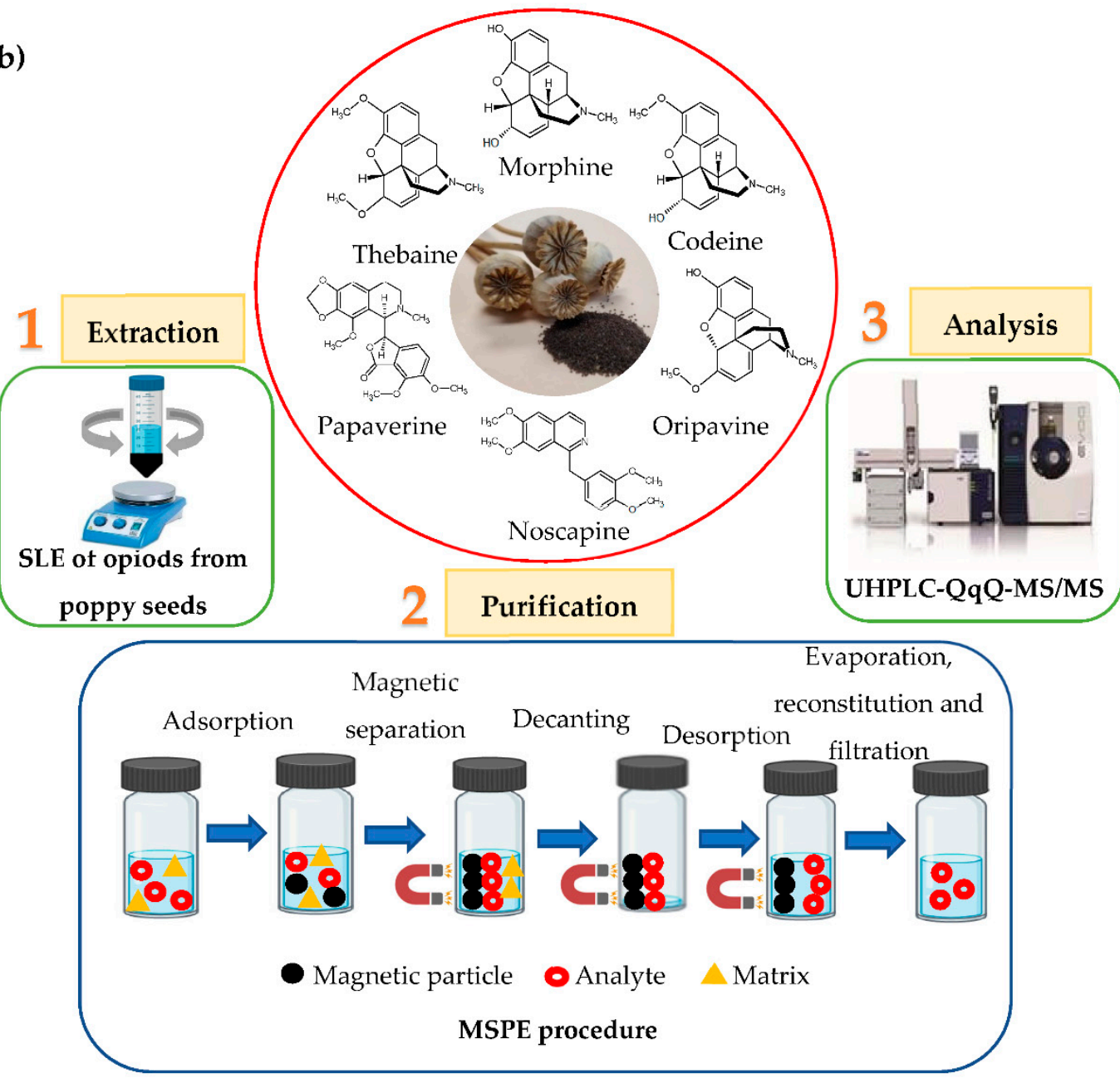

Figure 1. Schematic preparation process of the six types of magnetic particles synthesised (a). Diagram of proposed methodology to quantify opioids from poppy seeds: extraction (SLE), purification (MSPE) and analysis (UHPLC-QqQMS/MS) and chemical structures of the six most common opium alkaloids in contaminated poppy seeds (b).

\subsubsection{Preparation of $\mathrm{Fe}_{3} \mathrm{O}_{4}$ Particles}

First, $\mathrm{Fe}_{3} \mathrm{O}_{4}$ particles were prepared using chemical co-precipitation according to the work of Zhang and Shi [28]. Briefly, $15 \mathrm{mmol} \mathrm{FeCl}_{3} 6 \mathrm{H}_{2} \mathrm{O}$ and $10 \mathrm{mmol} \mathrm{FeCl}_{2} 4 \mathrm{H}_{2} \mathrm{O}$ were dissolved in $80 \mathrm{~mL}$ of deoxygenated water while stirring at $300 \mathrm{rpm}$ under nitrogen gas. The amount of $50 \mathrm{~mL}$ of ammonia solution (32\%) was dropwise added into the clear yellow 
solution and it turned black. The reaction was maintained at $80{ }^{\circ} \mathrm{C}$ for $30 \mathrm{~min}$. The black precipitates obtained $\left(\mathrm{Fe}_{3} \mathrm{O}_{4}\right.$ particles) were then collected with the help of a strong magnet and washed repeatedly with deionised water until the $\mathrm{pH}$ of the washings became neutral and finally dried under vacuum at $60{ }^{\circ} \mathrm{C}$ for $24 \mathrm{~h}$.

\subsubsection{Surface Modification of $\mathrm{Fe}_{3} \mathrm{O}_{4}$ Particles with Amorphous Silica $\left(\mathrm{Fe}_{3} \mathrm{O}_{4} @ \mathrm{SiO}_{2}\right)$}

The $\mathrm{Fe}_{3} \mathrm{O}_{4}$ particles were coated with amorphous silica $\left(\mathrm{SiO}_{2}\right)$ according to the reported method of Zeng et al. with minor modifications [29]. Briefly, $1.5 \mathrm{~g}$ of $\mathrm{Fe}_{3} \mathrm{O}_{4}$ particles were dispersed in $60 \mathrm{~mL}$ of isopropanol/ultra-pure water $(5 / 1, v / v)$ followed by ultrasonic dispersion for $20 \mathrm{~min}$. Then, under continuous stirring, $15 \mathrm{~mL}$ of ammonia solution and $8 \mathrm{~mL}$ of TEOS were promptly added. After that, the mixture solution was stirred at room temperature for $24 \mathrm{~h}$. Finally, the mixture was separated by an external magnetic field and the modified magnetic particles were washed with ultra-pure water, respectively, many times until the $\mathrm{pH}$ of the washing fluid was 7. Finally, the modified magnetic particles were dried under vacuum at $60{ }^{\circ} \mathrm{C}$ for $24 \mathrm{~h}$.

\subsubsection{Surface Modification of $\mathrm{Fe}_{3} \mathrm{O}_{4}$ Particles with Mesostructurated Silica $\left(\mathrm{Fe}_{3} \mathrm{O}_{4} @ \mathrm{SiO}_{2} @ \mathrm{mSiO}_{2}\right)$}

With the aim to obtain a material with a higher surface area that allows an increase in the functionalisation degree, $\mathrm{Fe}_{3} \mathrm{O}_{4} @ \mathrm{SiO}_{2}$ particles were coated with a layer of mesostructured silica $\left(\mathrm{mSiO}_{2}\right)$ according to the work of Deng et al., but with some modifications, as the amounts of the reagents were optimised [26]. Briefly, $3 \mathrm{~g}$ of $\mathrm{Fe}_{3} \mathrm{O}_{4} @ \mathrm{SiO}_{2}$ was dispersed in a mixed solution containing $160 \mathrm{~mL}$ of ultra-pure water, $120 \mathrm{~mL}$ ethanol, $1.4 \mathrm{~g} \mathrm{CTAB}$ and $12 \mathrm{~mL}$ ammonia solution. After the mixture was homogenised for $30 \mathrm{~min}, 6.4 \mathrm{~mL}$ of TEOS was dropwise added and stirred for $6 \mathrm{~h}$. The product was collected with the help of a magnet and washed with ethanol and methanol several times. The $\mathrm{Fe}_{3} \mathrm{O}_{4} @ \mathrm{SiO}_{2} @ \mathrm{CTAB} @ \mathrm{mSiO}_{2}$ particles were collected with the aid of a magnet and were calcined to remove the CTAB using a heating program from room temperature to $550^{\circ} \mathrm{C}$ at $1{ }^{\circ} \mathrm{C} / \mathrm{min}$ and holding the temperature for $4 \mathrm{~h}$.

2.3.4. Organic Functionalisation of $\mathrm{Fe}_{3} \mathrm{O}_{4} @ \mathrm{SiO}_{2}$ and $\mathrm{Fe}_{3} \mathrm{O}_{4} @ \mathrm{SiO}_{2} @ \mathrm{mSiO}_{2}$ Particles with $\mathrm{C}_{8}$ or $\mathrm{C}_{18}$ Groups

Both materials were functionalised with two different organic groups to compare. To carry this out, $0.5 \mathrm{~g}$ particles and $0.5 \mathrm{~g} \mathrm{C}_{8}$ or $\mathrm{C}_{18}$ were added to $30 \mathrm{~mL}$ of anhydrous toluene under a nitrogen atmosphere. The mixture was stirred at $80{ }^{\circ} \mathrm{C}$ for $24 \mathrm{~h}$. After the reaction, the particles were separated by an external magnetic field and were washed with toluene, ethanol and diethyl ether. Finally, the organic-functionalised magnetic amorphous and mesostructured particles were dried under vacuum at $60^{\circ} \mathrm{C}$ for $24 \mathrm{~h}$.

\subsection{Characterization of Organic-Functionalised Magnetic Particles}

Scanning electron microscopy (SEM) was recorded on Nova NanoSEM 230 FEI with an energy-dispersive spectrometry system (EDS). Previously, samples were treated with a sputtering method by dispersing the material in ethanol and coating the sample with a film thickness of $7 \mathrm{~nm}$ of gold. The samples were also characterised using XRD to evaluate the structure of the materials. Wide and low angle powder X-ray diffraction (XRD) patterns of the silicas were performed to determine if the material showed the typical spectrum of magnetite, which indicated that the magnetic core had not been disturb by the surface modification and if the material had a long mesoscopic ordered structure, respectively. XRD patterns were obtained on a Philips Diffractometer model PW3040/00 X'Pert MPD/MRD at $45 \mathrm{kV}$ and $40 \mathrm{~mA}$, using $\mathrm{Cu} \mathrm{K} \alpha$ radiation $(\lambda=1.5418 \AA)$. The samples were treated in power and placed in a sample holder. The sample and detector are rotated and the XRD patterns are collected from 0 to $10^{\circ}$ in the low angle and between 20 to $70^{\circ}$ in the wide angle. Iron and Silica $w t \%$ determination was carried out by X-ray fluorescence (XRF) using an X-ray fluorescence spectrophotometer Phillips MagiX with an X-ray source of $1 \mathrm{~kW}$ and a rhodium anode in a helium atmosphere. This quantification method can analyse 
from $0.0001 \%$ to $100 \%$ of Fe and Si. Infrared spectra were carried out on a Thermo Nicolet 380 Fourier-Transform Infrared (FT-IR) spectrophotometer in the region $4000-600 \mathrm{~cm}^{-1}$ using the ATR (Attenuated Total Reflection) technique to quantify the functional groups in the magnetic particles and to check the complete removal of the CTAB. For this, a small amount of sample (around $1 \mathrm{mg}$ ) previously vacuum-dried was used. The measures were performed at room temperature to avoid the signal of the physisorbed water and in the transmittance mode with 64 scans per spectrum at a resolution of $4 \mathrm{~cm}^{-1}$. Nitrogen gas adsorption-desorption isotherms were obtained using a Micromeritics ASAP 2020 analyser. These isotherms were measured at $-196{ }^{\circ} \mathrm{C}$ over the interval of relative pressures $\left(\mathrm{P} / \mathrm{P}_{\mathrm{o}}\right)$ from $10^{-4}$ to 0.994 . Before measurements, the samples were degassed in a vacuum at $80^{\circ} \mathrm{C}$ for $10 \mathrm{~h}$ in the port of degasification of the instrument. These temperatures were chosen to avoid any degradation of the organics groups and to remove adsorbed species, solvents and water. The Brunauer-Emmett-Teller (BET) method was utilised to calculate the specific surface areas $\left(\mathrm{S}_{\mathrm{BET}}\right)$. By using the Barrett-Joyner-Halenda $(\mathrm{BJH})$ model, the pore volumes and pore size distributions were derived from the desorption branches of isotherms and the total pore volumes $\left(\mathrm{V}_{\mathrm{t}}\right)$ estimated from the desorbed amount at a relative pressure $\mathrm{P} / \mathrm{P}_{\mathrm{o}}$ of 0.97 . In addition, this characterisation also allowed us to compare the surface areas and to optimise the amounts of TEOS and CTAB to be added at the mesostructured silica coating step. Finally, elemental analysis ( $\% \mathrm{H}, \% \mathrm{C}$ and $\% \mathrm{~N})$ was performed using a microanalyser Flash 2000 Thermo Fisher Scientific Inc. (Hampton, NH, USA) to determine the degree of functionalisation.

\subsection{Optimisation of UHPLC-QqQ-MS/MS Analysis}

The determination of opium alkaloids was achieved with a UHPLC system (Advance Elute, Bruker, Billerica, MA, USA) equipped with a PAL RSI Autosampler (containing a loop of $100 \mu \mathrm{L}$ ) coupled to a triple quadrupole tandem mass spectrometer detector (EVOQTM Elite, Bruker) with an electrospray ion source (ESI). Chromatographic separation was performed on an Intensity Solo $2 C_{18}$ column $(100 \mathrm{~mm} \times 2.1 \mathrm{~mm}$, Bruker, Billerica, MA, USA) at $30^{\circ} \mathrm{C}$. The injection volume was $10 \mu \mathrm{L}$ (partial injection) and the flow rate was kept constant in the mobile phase at $0.4 \mathrm{~mL} / \mathrm{min}$ during the analysis. A gradient elution was used by combining mobile phase $\mathrm{A}$ of water with mobile phase $\mathrm{B}$ of acetonitrile, both containing $0.1 \%$ formic acid. The linear gradient began in $95 \% \mathrm{~A}$, in minute 3.5 changed to $30 \% \mathrm{~A}$, in minute 3.7 returned to $95 \% \mathrm{~B}$ and then it was maintained in isocratic until minute 5 .

The detection of each analyte was determined by direct infusion of a standard solution in methanol of $1 \mu \mathrm{L} / \mathrm{mL}$ of each opium alkaloid using a syringe pump at a flow rate of $20.0 \mu \mathrm{L} / \mathrm{min}$. The mass spectrometer was operated in positive electrospray ion source mode (ESI+) with multiple reaction monitoring (MRM) using $\mathrm{N}_{2}$ as drying gas $\left(350{ }^{\circ} \mathrm{C}\right.$ and $40 \mathrm{psi}$ ); a cone temperature and gas pressure of $300^{\circ} \mathrm{C}$ and $20 \mathrm{psi}$, respectively; Ar as nebuliser (60 psi); and collision gas ( $2 \mathrm{mTorr}$ ) and ion spray voltage of $4200 \mathrm{~V}$; collected delay at $0.6 \mathrm{~min}$ with a detector voltage at $1.65 \mathrm{~V}$. Compounds were monitored with the transitions shown in Table S2.

\subsection{Optimisation of Sample Preparation}

For the optimisation of the sample preparation, firstly, the SLE parameters and, secondly, the MSPE purification parameters were optimised. The diagram for each of these steps is shown in Figure 1b.

\subsubsection{Optimisation of SLE of Opioids from Poppy Seeds}

First, the conditions for the SLE of opioids from poppy seeds were examined. The parameters that were optimised were the following: the mass of initial seeds $(1,2.5,5$ and $10 \mathrm{~g}$ ); the type of solvent (acetonitrile/water/formic acid 80/19/1, v/v/v, methanol, methanol/water 50/50, $v / v$ and methanol $0.1 \%$ acetic acid); the agitation type (ultrasound and magnetic stirring); the volume of solvent (10, 20 and $30 \mathrm{~mL})$; the extraction time $(10,20$, 
$30 \mathrm{~min}$ and $1 \mathrm{~h}$ ); the number of successive extractions (up to 6); and the $\mathrm{pH}$ of the solvent $(3,5,6.8$ and 10$)$.

2.6.2. Discontinuous Adsorption Studies to Select the Best Magnetic Material for MSPE Procedure

Secondly, discontinuous adsorption studies were performed with all the previously synthesised magnetic materials to evaluate their adsorption capacity and to choose the most suitable one for the subsequent MSPE process. For this purpose, $100 \mathrm{mg}$ of each of the six synthesised materials was added to $2 \mathrm{~mL}$ of different types of solvents (methanol/water $50 / 50, v / v$, acetonitrile/water/formic acid, $80 / 19 / 1, v / v / v$ and methanol $0.1 \%$ acetic acid) containing $1 \mu \mathrm{g} / \mathrm{mL}$ of each of the six analytes. Finally, the supernatants of each of the different solvent type were analysed by UHPLC-QqQ-MS/MS after a determined adsorption time $(0,1,5,10$ and $20 \mathrm{~min})$. All the studies were made in duplicate and the adsorption percentages of each of the materials on the different solvents were calculated and compared to determine which material and solvent were the best.

\subsubsection{Adsorption Kinetic and Isotherm Experiments with $\mathrm{Fe}_{3} \mathrm{O}_{4} @ \mathrm{SiO}_{2} @ \mathrm{mSiO}_{2}$ Material}

The adsorption kinetics and isotherms were investigated with the material selected for the MSPE procedure.

For adsorption kinetics, $100 \mathrm{mg}$ of the material was added to a solution containing each of the six analytes $(2 \mathrm{~mL}, 1 \mu \mathrm{g} / \mathrm{mL})$. The mixtures were shaken at different times (1-20 $\mathrm{min}$ ) and the supernatants in equilibrium were analysed by UHPLC-QqQ-MS/MS. The adsorption capacity was calculated by Equation (S1) in Table S3. The adsorption kinetics were determined by Langergren's pseudo-first-order [30], pseudo-second-order [31] and intra-particle diffusion kinetic models [32] (Table S3).

For adsorption isotherm, a series of $2.0 \mathrm{~mL}$ solutions of different concentrations of the six analytes $(0.1-50 \mu \mathrm{g} / \mathrm{mL})$ were added to $100 \mathrm{mg}$ of the material under optimum time. The isotherms of the six opium alkaloids adsorption on the magnetic particles were analysed using the commonly used Langmuir [33] and Freundlich [34] models (Table S3).

\subsubsection{Optimisation of MSPE Conditions with $\mathrm{Fe}_{3} \mathrm{O}_{4} @ \mathrm{SiO}_{2} @ \mathrm{mSiO}_{2}$ Material}

Conditions of the MSPE procedure were optimised. For this purpose, $2 \mathrm{~mL}$ of $1 \mu \mathrm{g} / \mathrm{mL}$ of each of the six analytes was used. The parameters of the MSPE procedure that were optimised were the following: the amount of adsorbent (between 25 and $100 \mathrm{mg}$ ); the adsorption time (from 1 to $20 \mathrm{~min}$ ); the $\mathrm{pH}$ of the initial solution (ranging from 3 to 10); the desorption eluent (diethyl ether, dichloromethane, chloroform, isopropanol, acetonitrile, methanol, water, ethyl acetate and ethanol) with different percentages of acid (formic acid) or base (ammonia) between 0.1 and $20 \%$ or mixtures of some of these solvents at different proportions $(50 / 50,80 / 20$ or $20 / 80, v / v)$; the volume of the desorption eluent (from 2 to $5 \mathrm{~mL}$ ); and the number of successive desorptions (up to 5). All studies were carried out in triplicate. One factor at a time method was employed to obtain the optimal conditions of each parameter.

\subsection{Optimised Sample Preparation Procedure}

\subsubsection{Optimised SLE of Opioids from Poppy Seeds}

In the SLE of opioids from poppy seeds, $2.5 \mathrm{~g}$ of seeds were extracted with $30 \mathrm{~mL}$ of methanol/water, 50/50 (v/v). The mixture was vortexed for $30 \mathrm{~s}$ and for $30 \mathrm{~min}$ it was stirred magnetically. Later the supernatant was recovered and a second extraction was carried out in the same conditions. Finally, the two supernatants were put together and $2 \mathrm{~mL}$ were taken for purification through the MSPE.

\subsubsection{Optimised MSPE Procedure}

The steps that were carried out in the MSPE procedure are shown in Figure 1b. In the first place, $50 \mathrm{mg}$ of $\mathrm{Fe}_{3} \mathrm{O}_{4} @ \mathrm{SiO}_{2} @ \mathrm{mSiO}_{2}$ were added with the extraction supernatant 
and then the mixture was treated with 1 min ultrasonication until the analytes arrived at an adsorption equilibrium with the adsorbent material. Then, with the help of a magnet, the solution was decanted and the analytes were eluted from the magnetic particles with $2 \mathrm{~mL}$ of diethyl ether/methanol $80 / 20$, v/v by ultrasound for $1 \mathrm{~min}$. Later the supernatant was recovered and a second desorption was carried out in the same conditions. Finally, $2 \mathrm{~mL}$ of these supernatants with the analytes was vacuum evaporated, $50 \mu \mathrm{L}$ of a $1 \mu \mathrm{g} / \mathrm{mL}$ solution of morphine-D3 was added, reconstituted in $1 \mathrm{~mL}$ and then filtered and analysed by HPLC-QqQ-MS/MS.

\subsection{Instrumental and Method Validation}

The present methodology was validated in terms of linearity, method and instrumental detection (LOD, MDL) and quantification (LOQ, MQL) limits, matrix effects, accuracy, precision and selectivity. For more details, see Section S1.1 in Supplementary Materials. Since there is no official regulation for validation methodologies for quantified opium alkaloids in poppy seeds, the validation was conducted according to the criteria established in SANTE/11813/2017 document for the analytical quality control of pesticide residues in food and feed [35] and EC No 401/2006 [36] establishing the methods of sampling and analysis for the official control of the levels of mycotoxins in foodstuffs.

For the validation process, the commercial poppy seed sample PS05 (Table S1) was used since it had low levels of alkaloids. In addition, a double wash with water at $100{ }^{\circ} \mathrm{C}$ for $30 \mathrm{~min}$ was applied. Signals of the analytes obtained were subtracted when required.

\section{Results and Discussion}

\subsection{Characterisation of Magnetic Materials Synthetised \\ 3.1.1. SEM}

The morphology of the synthesised particles can be observed from the SEM images in Figure S1. The particles have a spherical morphology and have resulted in a considerable growth in size after the surface modification. The initial $\mathrm{Fe}_{3} \mathrm{O}_{4}$ particles have a size of approximately $20 \mathrm{~nm}$ and the modified particles with amorphous silica $\left(\mathrm{Fe}_{3} \mathrm{O}_{4} @ \mathrm{SiO}_{2}\right)$ have a size in the range of $0.55-0.91 \mu \mathrm{m}$ and with mesostructured silica $\left(\mathrm{Fe}_{3} \mathrm{O}_{4} @ \mathrm{SiO}_{2} @ \mathrm{mSiO}_{2}\right)$ of 1.00-1.36 $\mu \mathrm{m}$. This demonstrated the successful modifications of material as there is a growth in size with the first coating and another growth with the second coating.

\subsubsection{XRD}

The XRD patterns of the synthesised magnetic particles are shown in Figure S2. The low-angle XRD pattern reveals the Miller index (100) characteristic of materials with mesoscopic order. In addition, there are several relatively strong diffraction peaks in the $2 \theta$ region of $20-70^{\circ}$, which are similar to those of the $\mathrm{Fe}_{3} \mathrm{O}_{4}$ particles reported by other groups [26,37,38], with the six discernible diffraction peaks 220,311, 400, 422, 511 and 440 that correspond with the Miller index diffraction peaks that appears in the database of magnetite in JCPDS (JCPDS card: 19-629) file. This finding proved that all the silica-coated magnetic particles were composed of $\mathrm{Fe}_{3} \mathrm{O}_{4}$ core. Moreover, the peak positions of the XRD patterns between different materials remain unchanged, which indicates that the magnetic core had not been disturb by the surface modification. This is also observed during the MSPE procedure. Although the separation rate was gradually reduced with the surface modification of $\mathrm{Fe}_{3} \mathrm{O}_{4}$, the magnetism of the functionalised particles is still strong enough that magnetic decantation with the external magnet can be performed quickly and without sample loss.

\subsubsection{XRF}

$X$-ray fluorescence measurement was made to determine the concentration (\%) of iron and silica in all the materials synthesised. The percentage of iron decreased from 57.8 in $\mathrm{Fe}_{3} \mathrm{O}_{4}$ to 31-34\% in the functionalised particles covered with amorphous silica (with $15-14 \% \mathrm{Si}$ ) and to $13-20 \%$ (with $20-19 \% \mathrm{Si}$ ) in the mesostructured silica shell functionalised 
particles. Nevertheless, the amount of iron in the materials after functionalisation is still large enough to confer high magnetism and to ensure a quick and easy separation of the microparticles from the solution in the MSPE procedure with the use of a strong magnet.

\subsubsection{FT-IR}

An important aspect to consider before the functionalisation of the particles with the $\mathrm{C}_{8}$ or $\mathrm{C}_{18}$ ligands is the successful removal of the CTAB. To perform this, the amount of $\mathrm{CTAB}$ present in the materials was monitored after the removal treatment by using FT-IR spectroscopy before the functionalisation process by checking the presence of the bands of the $-\mathrm{CH}_{2}$ and $-\mathrm{CH}_{3}$ groups from $\mathrm{CTAB}$ at $2855 \mathrm{~cm}^{-1}$ and $2925 \mathrm{~cm}^{-1}$, respectively. The first treatment was performed with a Soxhlet acetone extraction, as in most studies $[22,23,36,37]$. However, the intensity of these bands was remarkable (Figure S3a, spectrum 2), which showed that this treatment was not effective in eliminating the surfactant. For this reason, in this work, we use a calcination treatment as an effective method for the complete elimination of rest of CTAB remaining inside the porous structure of the materials. This was confirmed by the absence of the C-H bands, as can be observed in Figure S3a, spectrum 1 .

In addition, the materials synthesised in this study were characterised by ATR-FT-IR. The results of each magnetic material are shown in Figure S3b. The absorption peak that can be seen starting around $600 \mathrm{~cm}^{-1}$ in all the spectra was attributed to the $\mathrm{Fe}-\mathrm{O}-\mathrm{Fe}$ vibration. This band confirms the existence of a magnetic core of $\mathrm{Fe}_{3} \mathrm{O}_{4}$ in all the particles. The successful surface modification with silica of the magnetic particles can be confirmed with the appearance of the Si-O-Si band at $1090 \mathrm{~cm}^{-1}$ in all the modified materials. After functionalisation, the organic groups of $\mathrm{C}_{8}$ and $\mathrm{C}_{18}$ showed two new peaks appearing at $2855 \mathrm{~cm}^{-1}$ and $2925 \mathrm{~cm}^{-1}$ due to the $\mathrm{C}-\mathrm{H}$ stretching bands of the $-\mathrm{CH}_{2}$ - and $-\mathrm{CH}_{3}$ groups. The peak intensity of these bands in the materials functionalised with $\mathrm{C}_{18}$ is higher than that functionalised with $\mathrm{C}_{8}$ because of the larger number of $-\mathrm{CH}_{2}$ - and $-\mathrm{CH}_{3}$ groups in the $\mathrm{C}_{18}$ ligand (Figure S3b, spectrums 4 and 5, 6 and 7). Moreover, the intensity of this band is higher in the particles modified with mesostructured silica than with amorphous silica (spectrum 6 compared to 4 and 7 compared to 5), which can be attributed to a higher functionalisation degree, which is in accordance with the results obtained in the elemental analysis (Table 1).

Table 1. Textural properties of the six magnetic materials synthesised.

\begin{tabular}{|c|c|c|c|c|c|c|c|}
\hline \multirow{2}{*}{ Material } & \multirow{2}{*}{$\mathrm{S}_{\mathrm{BET}}\left(\mathrm{m}^{2} / \mathrm{g}\right)^{\mathrm{a}}$} & \multirow{2}{*}{$\begin{array}{l}\text { Pore Volume } \\
\quad\left(\mathrm{cm}^{3} / \mathrm{g}\right)^{b}\end{array}$} & \multirow{2}{*}{$\begin{array}{l}\text { Pore Diameter } \\
\text { (Å) }{ }^{c}\end{array}$} & \multicolumn{4}{|c|}{ Elemental Analysis (\%) } \\
\hline & & & & $\mathrm{C}$ & $\mathbf{N}$ & $\mathrm{H}$ & (mmol ligand/g) ${ }^{d}$ \\
\hline $\mathrm{Fe}_{3} \mathrm{O}_{4}$ & - & - & - & - & - & - & - \\
\hline $\mathrm{Fe}_{3} \mathrm{O}_{4} @ \mathrm{SiO}_{2}$ & 147 & 0.18 & 125.8 & - & - & - & - \\
\hline $\mathrm{Fe}_{3} \mathrm{O}_{4} @ \mathrm{SiO}_{2} @ \mathrm{C}_{8}$ & 26 & 0.09 & 124.4 & 3.432 & 0.000 & 1.070 & 0.286 \\
\hline $\mathrm{Fe}_{3} \mathrm{O}_{4} @ \mathrm{SiO}_{2} @ \mathrm{C}_{18}$ & 24 & 0.10 & 124.9 & 3.227 & 0.000 & 0.928 & 0.134 \\
\hline $\mathrm{Fe}_{3} \mathrm{O}_{4} @ \mathrm{SiO}_{2} @ \mathrm{mSiO}_{2}$ & 355 & 0.23 & 38.9 & - & - & - & - \\
\hline $\mathrm{Fe}_{3} \mathrm{O}_{4} @ \mathrm{SiO}_{2} @ \mathrm{mSiO}_{2} @ \mathrm{C}_{8}$ & 191 & 0.14 & 39.0 & 10.426 & 0.000 & 2.174 & 0.869 \\
\hline $\mathrm{Fe}_{3} \mathrm{O}_{4} @ \mathrm{SiO}_{2} @ \mathrm{mSiO}_{2} @ \mathrm{C}_{18}$ & 14 & 0.04 & 36.4 & 11.310 & 0.000 & 2.178 & 0.471 \\
\hline
\end{tabular}

${ }^{\mathrm{a}} \mathrm{S}_{\mathrm{BET}}$ : Specific surface area calculated by Brunauer-Emmett-Teller (BET) method. ${ }^{\mathrm{b}}$ Total pore volume was measured at relative pressure $\left(\mathrm{P} / \mathrm{P}_{0}\right)=0.97 .{ }^{\mathrm{c}}$ Pore diameter estimated by using the BJH (Barrett, Joyner and Halenda) model applied on the desorption Branch. ${ }^{\mathrm{d}} \mathrm{mmol}$ of ligand/g of material calculated with the $\%$ obtained by elemental analysis.

\subsubsection{BET}

BET characterisation was used to optimise the amount of TEOS and CTAB for coating the magnetic core with a mesostructured silica layer. When coating the $\mathrm{Fe}_{3} \mathrm{O}_{4}$ particles with the amounts of TEOS and CTAB used in the literature [26], a considerable loss of magnetism of the particles was observed and, therefore, much of the material was lost in the washing stage of the material by magnetic decantation, which resulted in a very low yield of the synthesis. In the washes, it was visually observed that different fractions of particles were formed, some were more coated with mesostructured silica than others and therefore with different levels of magnetism. As shown in Figure S4, the first fraction was darker brown and the second and third (less magnetic) fractions were considerably 
more whitish due to an excess of the silica layer. In order to check this, BET surface area measurements were performed on the first three fractions, showing the following surface area results: $380 \mathrm{~m}^{2} / \mathrm{g}$ for the first wash, $835 \mathrm{~m}^{2} / \mathrm{g}$ for the second wash and $790 \mathrm{~m}^{2} / \mathrm{g}$ for the third wash. This showed that TEOS and CTAB were added in excess, resulting in a lower yield and a non-homogeneous coating; therefore, in order to avoid this issue, the contents of these two reagents were reduced. The new amounts were compared with the original amount [26], with half and with a quarter of each of the two reagents, and the surface areas were compared. It was found that the surface area did not change significantly $\left(219,205\right.$ and $314 \mathrm{~m}^{2} / \mathrm{g}$, respectively) and that decreasing the amount of reagent resulted in a higher yield since fewer particles were lost by magnetic decantation. Thus, syntheses of $\mathrm{Fe}_{3} \mathrm{O}_{4} @ \mathrm{SiO}_{2} @ \mathrm{mSiO}_{2}$ were carried out with a quarter of the amounts of TEOS and CTAB used in the literature [26].

In addition, $\mathrm{Fe}_{3} \mathrm{O}_{4} @ \mathrm{SiO}_{2}$ and $\mathrm{Fe}_{3} \mathrm{O}_{4} @ \mathrm{SiO}_{2} @ \mathrm{mSiO}_{2}$ were characterised before and after functionalisation. The $\mathrm{N}_{2}$ adsorption-desorption isotherms of the materials synthesised in this work are shown in Figure S5a and c. For all materials, its adsorption isotherm can be assigned as Type IV, according to the IUPAC classification [39], which is characteristic of mesoporous material. The isotherms show an initial part that is characteristic of monolayer adsorption and a significant increase in the amount adsorbed at intermediate relative pressures characteristic of a multilayer filling mechanism. In the case of $\mathrm{Fe}_{3} \mathrm{O}_{4} @ \mathrm{SiO}_{2}$ and their functionalised derivatives, they presented an $\mathrm{H} 3$ hysteresis loop with almost parallel branches confined to relative pressures between 0.8 and 1 . This hysteresis loop is characteristic of uniform pores with a slit-like structure. Results obtained a BET specific surface area $\left(\mathrm{S}_{\mathrm{BET}}\right)$ of $147 \mathrm{~m}^{2} / \mathrm{g}$ and a pore volume of $0.18 \mathrm{~cm}^{3} / \mathrm{g}$ for the non-functionalised and $26-24 \mathrm{~m}^{2} / \mathrm{g}$ and $0.09-0.10 \mathrm{~cm}^{3} / \mathrm{g}$ for the functionalised with $\mathrm{C}_{8}$ and $\mathrm{C}_{18}$, respectively, which demonstrates the correct functionalisation of the materials (Table 1). As shown in Figure S5b, materials with amorphous silica have a disorganised pore distribution (width of the peak at half of the height equals to $100 \AA$ ) because no template was used. Nonfunctionalised material presents most of its mesopores centred at $125 \AA$ and a small group of mesopores can also be observed at $35 \AA$. After the $C_{8}$ and $C_{18}$ functionalisation, the small pores at $35 \AA$ disappear and only the big pore at $125 \AA$ is shown (Figure S5b and Table 1). The reason for this is that a decrease in the pore volume and pore diameter takes place, which is indicative of the correct anchorage of both ligands into the pores of the materials.

On the other hand, the $\mathrm{Fe}_{3} \mathrm{O}_{4} @ \mathrm{SiO}_{2} @ \mathrm{mSiO}_{2}$ and their functionalised derivatives also reflected Type IV adsorption isotherm, but in this case with an H4 hysteresis loop. Results obtained a $S_{\text {BET }}$ of $355 \mathrm{~m}^{2} / \mathrm{g}$ and a pore volume of $0.23 \mathrm{~cm}^{3} / \mathrm{g}$ for the non-functionalised and 191-14 $\mathrm{m}^{2} / \mathrm{g}$ and $0.14-0.04 \mathrm{~cm}^{3} / \mathrm{g}$ for the functionalised with $\mathrm{C}_{8}$ and $\mathrm{C}_{18}$, respectively. This shows the correct functionalisation of the material and that the $\mathrm{C}_{8}$ ligand provides a greater surface area due to its smaller chain. The pore size distribution is close to the micropore range, unlike materials with amorphous silica. As can be observed in the pore size distribution (Figure S5d), these materials present most of their pores centred around $40 \AA$.

\subsubsection{Elemental Analysis}

The percentage of $C$ in each functionalised material, calculated by elemental analysis, showed different levels of functionalisation depending on the silica and organic group type, as shown in Table 1. Consequently, the material with the highest level of functionalisation was $\mathrm{Fe}_{3} \mathrm{O}_{4} @ \mathrm{SiO}_{2} @ \mathrm{mSiO}_{2} @ \mathrm{C}_{8}$ with $0.869 \mathrm{mmol} / \mathrm{g}$, followed by $\mathrm{Fe}_{3} \mathrm{O}_{4} @ \mathrm{SiO}_{2} @ \mathrm{mSiO}_{2} @ \mathrm{C}_{18}$ with $0.471 \mathrm{mmol} / \mathrm{g}, \mathrm{Fe}_{3} \mathrm{O}_{4} @ \mathrm{SiO}_{2} @ \mathrm{C}_{8}$ with $0.286 \mathrm{mmol} / \mathrm{g}$ and, finally, $\mathrm{Fe}_{3} \mathrm{O}_{4} @ \mathrm{SiO}_{2} @ \mathrm{C}_{18}$ with $0.134 \mathrm{mmol} / \mathrm{g}$, which is coherent seeing the $\mathrm{S}_{\mathrm{BET}}$. By observing these results, it can be confirmed that the use of mesostructured silica permits a higher level of functionalisation than amorphous silica. Concerning the ligand, the one that provides the higher levels is $\mathrm{C}_{8}$. This may be because it is less voluminous due to its shorter chain and has greater accessibility through the pores of the material, allowing for a higher level of functionalisation. 


\subsection{Optimisation of UHPLC-QqQ-MS/MS Analysis}

Triple quadrupole mass spectrometric parameters were optimised for analytes in positive ionization mode by direct infusion of a standard solution in methanol of $1 \mu \mathrm{g} / \mathrm{mL}$ of each opium alkaloid using a syringe pump at a flow rate of $20.0 \mu \mathrm{L} / \mathrm{min}$. The molecular ion of each compound was detected with a $Q_{1}$ resolution of 0.7 at a scan time of $500 \mathrm{~ms}$ and to obtain the maximum intensity of the fragment ions of each analyte while the collision energy was optimised. For chromatographic separation, two mobile phases were tested by using acetonitrile or $\mathrm{MeOH}$ as eluent $\mathrm{B}$ and, in both cases, water as eluent $\mathrm{A}$, with $0.1 \%$ formic acid for both. The results were better with acetonitrile than methanol because of their best peak intensity and separation. Successive gradients were tested and, finally, the separation of the six analytes was achieved in only $5 \mathrm{~min}$ with the following gradient: $5-70 \% \mathrm{~B}(0-3.5 \mathrm{~min}), 70-5 \%$ (3.5-3.7 $\mathrm{min})$ and $5 \%$ (3.7-5 $\mathrm{min})$. Table S2 lists the parent ion, daughter ion and collision energy $(\mathrm{eV})$ optimal for MRM detection mode and the retention time of the opium alkaloids.

\subsection{Optimisation of Sample Preparation}

\subsubsection{Optimisation of SLE of Opioids from Poppy Seeds}

Many protocols in the literature have been examined for the extraction of opioids from poppy seeds. Some of them have used a large amount of sample and organic solvents, for example, a double extraction with $100 \mathrm{~mL}$ of acetonitrile/water/acid formic 80/19/1 (v/v/v) to extract $10 \mathrm{~g}$ poppy seeds [1]. In order to minimise the costs and negative impact on the environment, an attempt was made to reduce the amount of sample to be used and, with it, the amount of organic solvents. For this reason, the first SLE experiment was carried out in triplicate with 1, 2.5, 5 and $10 \mathrm{~g}$ of sample with $10 \mathrm{~mL}$ of acetonitrile/water/acid formic 80/19/1 (v/v/v) and for four different extraction times (2.5, 5, 10 and $20 \mathrm{~min})$. As a result, very high RSD values, especially with $1 \mathrm{~g}$ sample (mean values for all analytes were $82,66,53$ and $71 \%$ for each time, respectively), were observed. However, with $2.5 \mathrm{~g}$ of sample, the RSD was lowered (between 16 and 26\%) but was not improved with 5 and $10 \mathrm{~g}$ of sample. This dispersion in the results could be due to the variability in the opioid content of seeds from the same batch, as the contamination of each seed with plant latex could not be the same as it depends on many different factors (mainly genetic factors and environmental conditions) so that their contamination is finally very heterogeneous. Therefore, it was decided that it was sufficient to use a $2.5 \mathrm{~g}$ sample in order to minimise the use of environmentally harmful organic solvents.

Concerning the extraction solvent in the literature, many authors use methanol to extract opioids from poppy seeds $[9,17,40-42]$. Others use acidified methanol $[6,43]$ or a mixture of acetonitrile/water/formic acid 80/19/1(v/v/v) [1]. For this reason, in the present study, these three types of solvents were evaluated in two agitation modes, ultrasound (US) and magnetic stirring with $2.5 \mathrm{~g}$ of poppy seeds and $10 \mathrm{~mL}$ of solvent during $10 \mathrm{~min}$. In addition, the solvent methanol/water 50/50 (v/v) was added because it was the medium where the standards were dissolved and conserved in a stable form. As shown in Figure S6, not much difference was shown between acetonitrile/water/formic acid 80/19/1 (v/v/v) and methanol/water 50/50 (v/v) (although acetonitrile was better for morphine and noscapine). Thus, the solvent finally used for this purpose will depend on the medium that best favours the subsequent adsorption step in the MSPE procedure to avoid the evaporation process and to use less organic solvent.

Successive extractions were then performed to find out how many extractions were needed to complete the extraction. Six successive extractions were carried out with $20 \mathrm{~mL}$ of methanol/water $50 / 50(v / v)$ for 10 min under magnetic stirring and complete extraction was not obtained. In the first extraction, most of the opioids present in the seeds were extracted and, from the third extraction, the values obtained were very low and constant and, thus, it was not considered from the third extraction onwards. Furthermore, the same study was carried out with acetonitrile/water/formic acid, 80/19/1 (v/v/v) and similar 
results were obtained. Therefore, a double extraction with methanol/water 50/50 (v/v) was proposed.

Afterwards, the solvent volume and the extraction time were optimised. For this purpose, different combinations of double extractions were made with methanol/water $50 / 50(v / v)$ in magnetic stirring where the volumes tested were 10, 20 and $30 \mathrm{~mL}$ and times 10, 20, $30 \mathrm{~min}$ and $1 \mathrm{~h}$. As shown in Figure S7, as the solvent volume increased and the amount of opioids extracted increased considerably. In the same manner, the more time was used, the more was extracted, except from $30 \mathrm{~min}$ to $1 \mathrm{~h}$ where there was no increase in extraction. Furthermore, once the extraction volume and time were optimised, an additional third extraction was performed and only one residual area was observed; therefore, a decision was made to perform only two extractions of $30 \mathrm{~mL}$ during $30 \mathrm{~min}$.

Finally, the $\mathrm{pH}$ value of the extraction solvent $(\mathrm{pH} 3,5,6.8$ and 10) was studied. Thus, double extraction of $30 \mathrm{~mL}$ methanol/water 50/50 (v/v) for $30 \mathrm{~min}$ in magnetic stirring with different $\mathrm{pH}$ value: 3, 5, 6.8 (non-modified) and 10 was carried out. In order to obtain the acidified $\mathrm{pH}$, formic acid was used and, for the basic $\mathrm{pH}$, ammonia. As can be observed in Figure S8, with the unmodified solvent ( $\mathrm{pH}$ 6.8) higher extractions were obtained for all the analytes.

3.3.2. Selecting the Best Material for the MSPE Procedure after Making Discontinuous Adsorption Study with the Synthesised Magnetic Materials

In order to select the best magnetic material to conduct the MSPE procedure, a discontinuous adsorption study was carried out with $2 \mathrm{~mL}$ of methanol/water 50/50 (v/v), with $1 \mu \mathrm{g} / \mathrm{mL}$ of each of the six analytes and $100 \mathrm{mg}$ of each of the material synthetised. This adsorption medium was selected because it was the medium where the working standard solutions were prepared and were, therefore, soluble and stable and $100 \mathrm{mg}$ of material was used because it was the maximum quantity of the material expected to carry out the MSPE procedure. As can be seen in Figure 2, the result was that the three materials synthesised coated with mesostructured silica showed lower area values of the supernatant as the adsorption time increases and, with it, higher percentages of adsorption than amorphous silica materials. This agrees with the characterisation results since the mesostructured silica-coated material had a larger surface area than amorphous silica-coated material (355 vs. $147 \mathrm{~m}^{2} / \mathrm{g}$ ). In addition, more adsorption was obtained with non-functionalised materials than functionalised materials with $C_{8}$ and $C_{18}$ group.

In order to confirm the higher adsorption of non-functionalised material, an additional experiment was carried out with the three mesostructured materials with different adsorption media. The solvents selected to carry out the adsorption step with the material were the two solvents that showed similar results in the extraction of the opioids from the seeds, acetonitrile/water/formic acid 80/19/1 (v/v/v) and methanol 0.1\% acetic acid (Figure 3). Therefore, the results obtained previously with methanol/water 50/50 $(v / v)$ were compared with the results obtained with acetonitrile/water/formic acid 80/19/1 (v/v/v) and with acidified methanol $0.1 \%$ acetic acid. By comparing Figure 2 (orange colour) and Figure 3, with all solvents, more adsorption (\%) was observed with the non-functionalised material. This can be due to two possible reasons: When functionalising, the pore size has been reduced so much that the molecules do not penetrate and only a surface interaction takes place or the analytes do not interact effectively with the $\mathrm{C}_{8}$ and $\mathrm{C}_{18}$ groups. Therefore, to carry out the MSPE, the material $\mathrm{Fe}_{3} \mathrm{O}_{4} @ \mathrm{SiO}_{2} @ \mathrm{mSiO}_{2}$ was finally selected. In addition, the results were significantly better with methanol/water 50/50 (v/v) than with the other two solvents. Therefore, this solvent mixture was selected to carry out the adsorption step of the MSPE as for the extraction of opioids in the poppy seeds to avoid the evaporation step. 


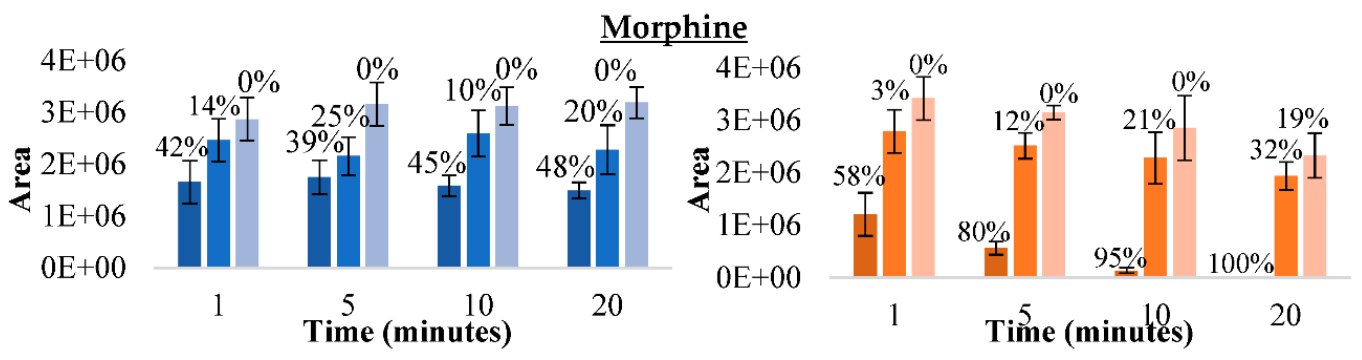

\section{Codeine}
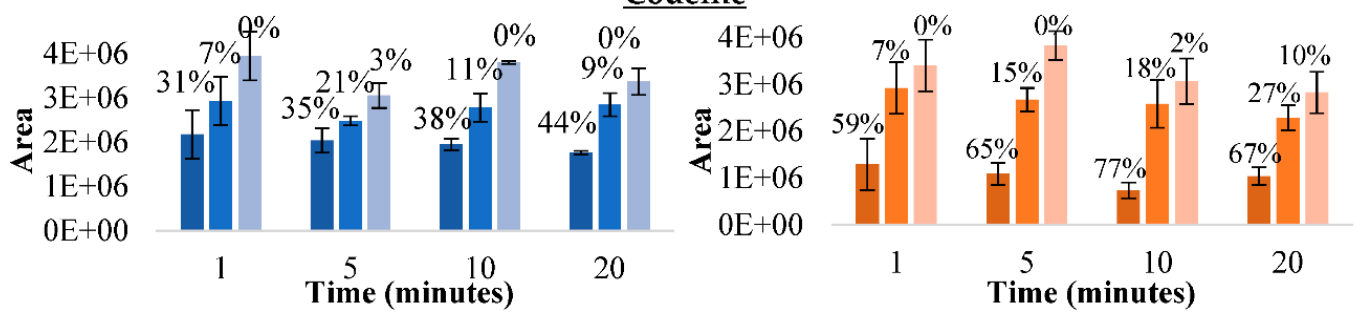

Thebaine
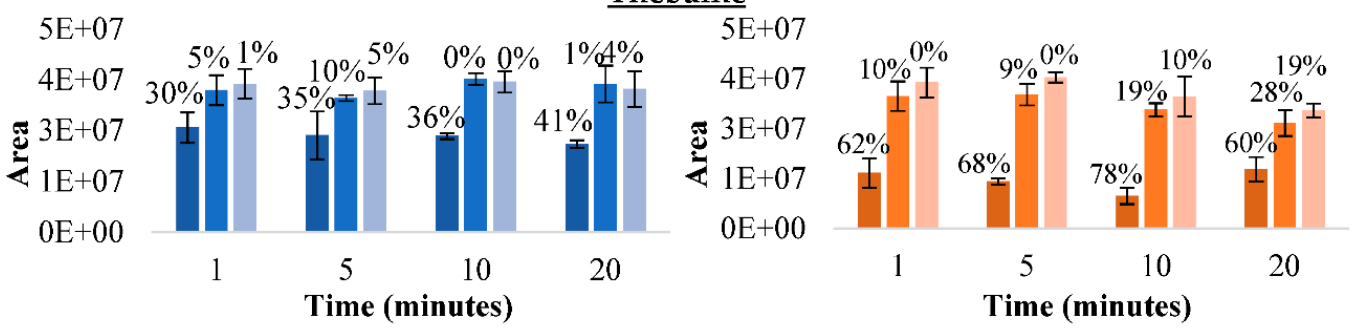

\section{Papaverine}
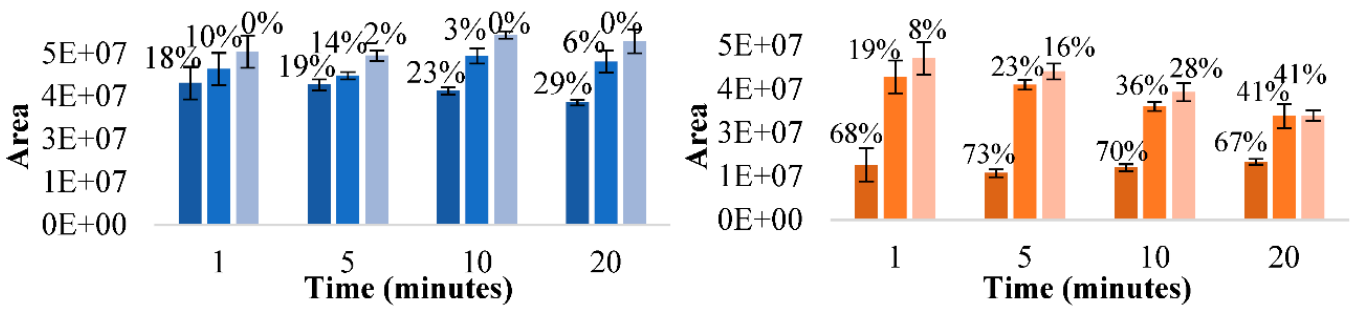

Noscapine
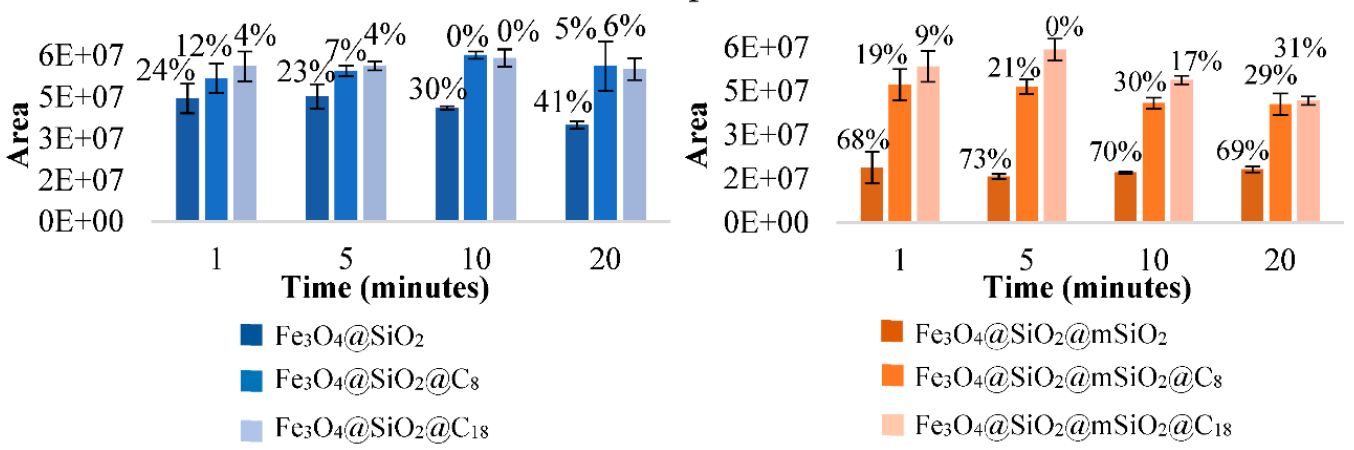

Figure 2. Areas of the supernatant with their respective percentages of adsorption (\%) at different times with each of the three amorphous silica materials (blue colour) and mesostructured silica magnetic materials (orange colour) with methanol/water $50 / 50(v / v)$ as the adsorption solvent. 


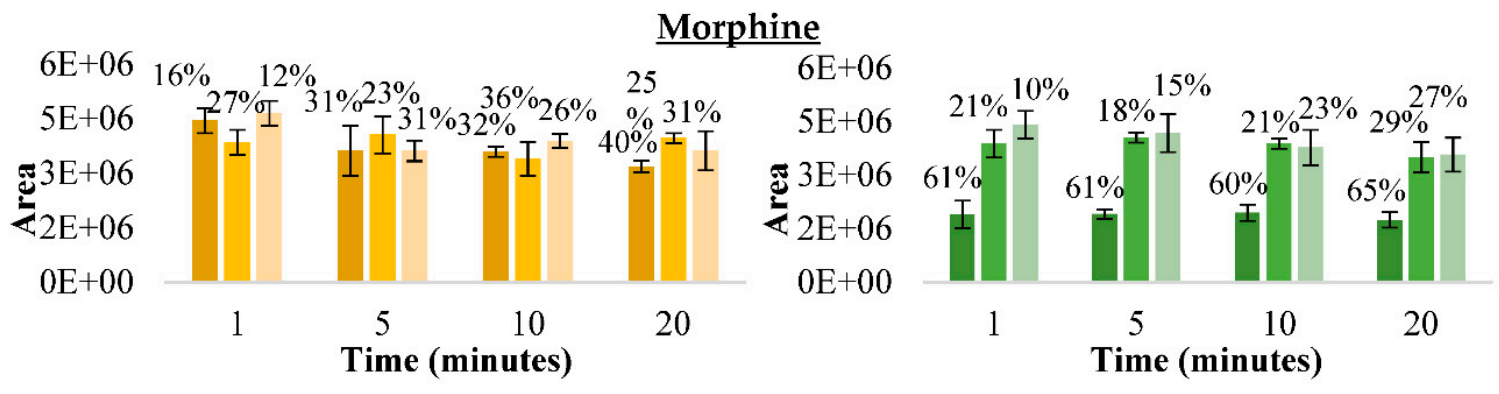

Codeine
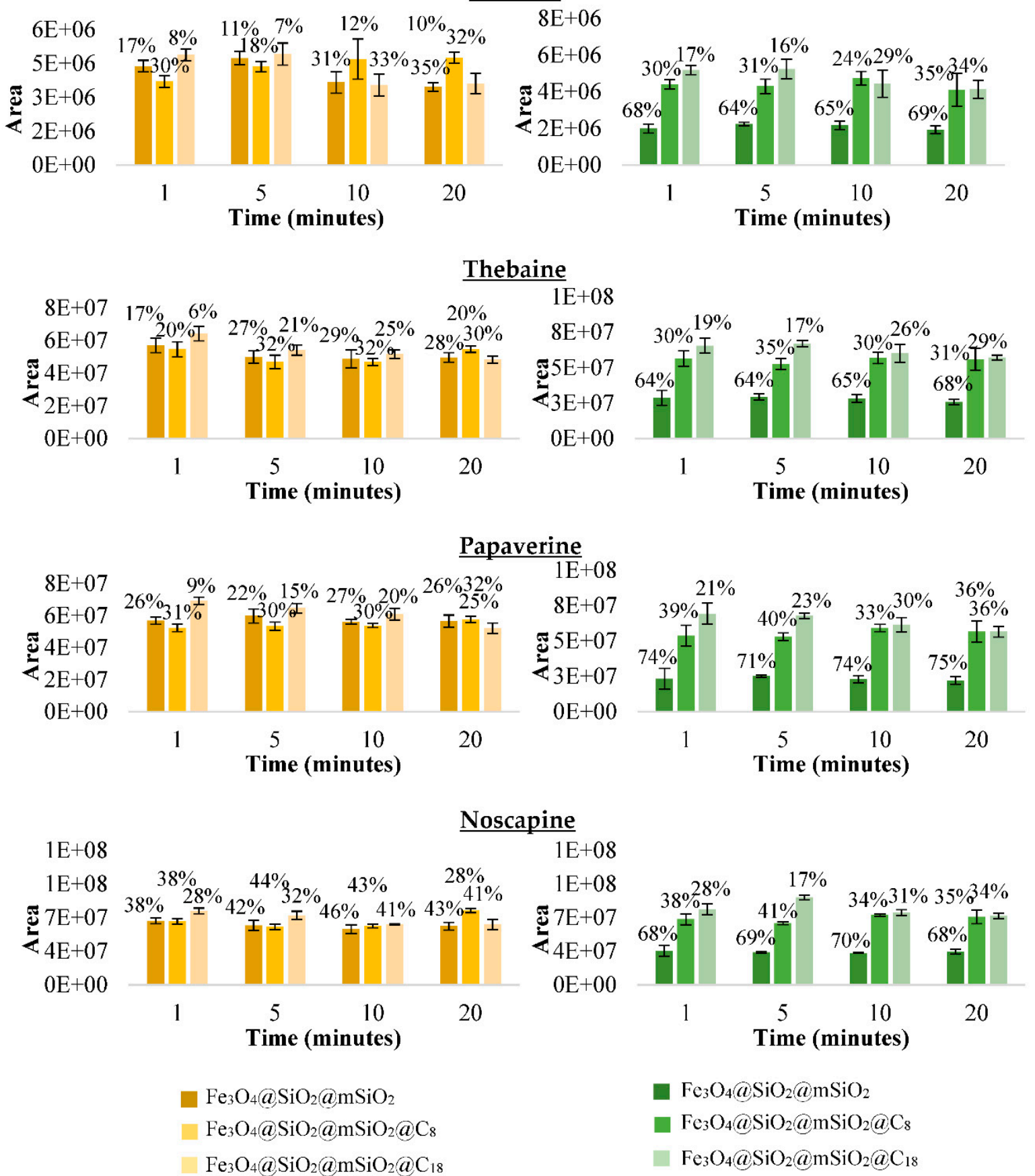

- $\mathrm{Fe}_{3} \mathrm{O}_{4} @ \mathrm{SiO}_{2} @ \mathrm{mSiO}_{2}$

- $\mathrm{Fe}_{3} \mathrm{O}_{4} @ \mathrm{SiO}_{2} @ \mathrm{mSiO}_{2} @ \mathrm{C}_{8}$

$\mathrm{Fe}_{3} \mathrm{O}_{4} @ \mathrm{SiO}_{2} @ \mathrm{mSiO}_{2} @ \mathrm{C}_{18}$

Figure 3. Areas of the supernatant with their respective percentages of adsorption (\%) at different times with each of the three mesostructured silica magnetic materials with different adsorption solvent: acetonitrile/water/formic acid $90 / 19 / 1(v / v / v)$ (yellow colour) and methanol acidified with $0.1 \%$ acid acetic (green colour). 


\subsubsection{Adsorption Kinetic and Isotherm Experiments of $\mathrm{Fe}_{3} \mathrm{O}_{4} @ \mathrm{SiO}_{2} @ \mathrm{mSiO}_{2}$ Material}

As shown in Figure S9a, the adsorption kinetics of the six opioid alkaloids is fast. In the first minute, almost all the adsorption is obtained and, in the following minutes, it was similar. However, in morphine and oripavine, there is a considerable increase in adsorption at minute 20 with respect to minute 1 and so it was decided to take $20 \mathrm{~min}$ as the adsorption time for the rest of the experiments at the moment. The adsorption kinetics were determined by Langergren's pseudo-first-order [30], pseudo-second-order [31] and intra-particle diffusion kinetic models [32], according to the Equations (S2)-(S4) in Table S3. The results were shown in Figure S10a and the important data of the three kinetic models were compiled in Table S4. The linear regression coefficients $\left(R^{2}\right)$ were more close to 1 in the pseudo-second-order model and their $\mathrm{Q}_{\mathrm{e}}$, cal (calculated result) was more similar to $\mathrm{Q}_{\mathrm{e}, \exp }$ (experiment result). For these reasons, the adsorption of the six opium alkaloids accorded mostly to the pseudo-second-order kinetics, indicating a chemical adsorption mechanism [37]. In addition, morphine and oripavine were the analytes with the highest

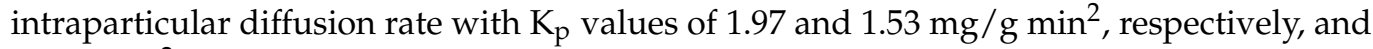
showed $\mathrm{R}^{2}$ close to 1 (Table $\mathrm{S} 4$ ), unlike the rest of the analytes that did not show this trend.

The adsorption isotherms were analysed by Langmuir [33] and Freundlich [34] models, according to the Equations (S5) and (S6) in Table S3. As shown in Figure S9b, by increasing the concentration of opioids in the equilibrium, the adsorption capacity was increased. In morphine, the maximum adsorption capacity was determined but, in the other opioids, it was still possible to adsorb more. As shown in Figure S10b, the $\mathrm{R}^{2}$ obtained by the Langmuir model was more close to 1 than by the Freundlich model. Thus, the adsorption occurred on the uniform monolayer surface of $\mathrm{Fe}_{3} \mathrm{O}_{4} @ \mathrm{SiO}_{2} @ \mathrm{mSiO}_{2}$ [37]. Equations (S1), (S5) and (S6) allowed the calculation of $\mathrm{Q}_{\max }$ and was 73.59, 102.04, 303.03, $303.03,107.353$ and $149.25 \mathrm{mg} / \mathrm{g}$ for morphine, codeine, thebaine, papaverine, noscapine and oripavine, respectively.

\subsubsection{Optimisation of MSPE Procedure with $\mathrm{Fe}_{3} \mathrm{O}_{4} @ \mathrm{SiO}_{2} @ \mathrm{mSiO}_{2}$ Material Adsorption Conditions (Time and $\mathrm{pH}$ )}

In order to determine the optimal adsorption time, different time ranges between 1 and $20 \mathrm{~min}$ were investigated with $100 \mathrm{mg} \mathrm{Fe} 3 \mathrm{O}_{4} @ \mathrm{SiO}_{2} @ \mathrm{mSiO}_{2}$ material. It can be seen in the adsorption kinetics of six opioid alkaloids in Figure S9a that the amounts of alkaloids adsorbed $\left(\mathrm{Q}_{\mathrm{t}}\right)$ at $1 \mathrm{~min}$ are similar to those adsorbed at $20 \mathrm{~min}$, except for morphine and oripavine which have slower adsorption kinetics and, at $20 \mathrm{~min}$, their maximum adsorption takes place. After determining that these two compounds have a higher intraparticle diffusion than the rest of the analytes (Section 3.3.3), in addition to evaluating the adsorption time in the highest or lowest level of adsorption of the analytes on the material, the influence of the adsorption time on the complete MSPE process was studied. For this purpose, the recoveries obtained at 1 and 20 min were calculated. In order to calculate them, the areas obtained by performing the complete MSPE procedure on a sample at a known concentration were compared with the areas of a blank sample subjected to the same extraction and purification process and spiked with the expected concentration. Finally, the recoveries of morphine and oripavine obtained after performing the complete MSPE procedure were lower at $20 \mathrm{~min}$ adsorption than at $1 \mathrm{~min}$ adsorption, approximately $20 \%$ versus $50 \%$, respectively. The possible reason for this may be that, with $20 \mathrm{~min}$ adsorption, a higher percentage of adsorption is obtained, but it penetrates so much into the pores (following the intra-particle model studied in Section 3.3.3) that later, in the desorption step, it cannot be desorbed. For this reason, the adsorption time of $1 \mathrm{~min}$ was selected for the MSPE procedure.

The influence of the $\mathrm{pH}$ of the sample solution on the efficiency of the MSPE process was investigated. For this purpose, $1 \mu \mathrm{g} / \mathrm{mL}$ of each of six opioids was in contact with $100 \mathrm{mg} \mathrm{Fe} \mathrm{O}_{4} @ \mathrm{SiO}_{2} @ \mathrm{mSiO}_{2}$ material in methanol/water 50/50 (v/v), with different $\mathrm{pH}$ values between 3.0 and 10.0 were studied for 1 min adsorption. Such as shown in Figure S11, there were no major differences between the values, especially in morphine and 
oripavine, which were very similar. In the other analytes, it was observed that the $\mathrm{pH} 6.8$ of the methanol/water 50/50 (v/v) without modification was the one that showed increased adsorbed area and with lower RSD, since the 7.6 showed more variation. For codeine, $\mathrm{pH} 6.8$ and 10 showed no differences and, for thebaine, $\mathrm{pH} 10$ facilitated the adsorption but, for papaverine and noscapine, it decreased and finally $\mathrm{pH} 6.8$ was selected as the best.

\section{Desorption Conditions (Solvent Type, Time, $\mathrm{pH}$ and Number of Consecutive Desorptions)}

The type of the desorption solvent selected is a critical parameter to obtain the highest possible desorption of the analytes and thus a higher recovery value (\%). First, the four solvents used in the SLE of poppy seeds at different desorption times $(1,5,10$ and $20 \mathrm{~min})$ were used with $20 \mathrm{~min}$ of adsorption time. As shown in Table S5, the recoveries obtained were low for morphine and oripavine. Therefore, it was determined that none of these solvents were effective for desorption. Consequently, eight solvents were studied (diethyl ether, dichloromethane, chloroform, isopropanol, acetonitrile, methanol, water and ethyl acetate) at $20 \mathrm{~min}$ desorption. All of them were used at three $\mathrm{pH}$ values, acidic with formic acid $1 \%$, without modification and basic with ammonia $1 \%$. With the first two conditions, it was not possible to desorb the analytes from the material obtaining low recoveries, for morphine and oripavine (around 1\%) and for the rest of the analytes less than $50 \%$. While the basic medium facilitated the desorption of the six opioids, the recoveries obtained were still low. Therefore, it was decided to increase the basicity of the medium by adding ammonia $10 \%$. As can be observed in Table S6, by increasing the ammonia content, the recoveries improved moderately. However, the recoveries were still low and so different mixtures were performed with the solvents that produced the best results, which included diethyl ether with methanol or acetonitrile and dichloromethane with methanol or acetonitrile at different proportions $(50 / 50,80 / 20$ and 20/80,v/v) and for different times (20, 40 and $60 \mathrm{~min})$. As shown in Table S7, the best combination was diethyl ether/methanol, 80/20 (v/v) as all analytes were around $100 \%$ recovery, except for morphine and oripavine, for which the maximum recovery was $37 \%$. The reason why desorption of these two analytes was so difficult might be because they showed high intraparticle diffusion (Section 3.3.3). Finally, the adsorption and desorption times were reduced and the study was carried out with $1 \mathrm{~min}$ of adsoption and with $1 \mathrm{~min}$ for up to five consecutive desorptions with diethyl ether/methanol 80/20 (v/v) with 10\% ammonia. As can be observed in Table S8, higher recoveries were obtained with short times in adsorption and desorption steps, between 76 and 109\% for all analytes, except for morphine and oripavine which reflected recoveries near $50 \%$. In addition, the increase the desorption solvent volume to double was also studied from $2 \mathrm{~mL}$ to $4 \mathrm{~mL}$. However, no better results were obtained. Therefore, the best option was to make triple desorption with $2 \mathrm{~mL}$ for $1 \mathrm{~min}$.

\section{Amount of $\mathrm{Fe}_{3} \mathrm{O}_{4} @ \mathrm{SiO}_{2} @ \mathrm{mSiO}_{2}$ Material}

In order to make the MSPE procedure effective and to obtain good results, different amounts of magnetic particles between 25 and $100 \mathrm{mg}$ were studied. Figure 4 shows the areas of desorbed opium alkaloids achieved with the different amounts of adsorbent material with their respective recovery values (\%). The amount selected to perform the MSPE procedure was $50 \mathrm{mg}$ of magnetic particles because with this amount 51, 64, 98, 101,76 and $48 \%$ recoveries for morphine, codeine, thebaine, papaverine, noscapine and oripavine, respectively, were achieved. Increasing the amount of adsorbent material above this did not significantly improve the results. 

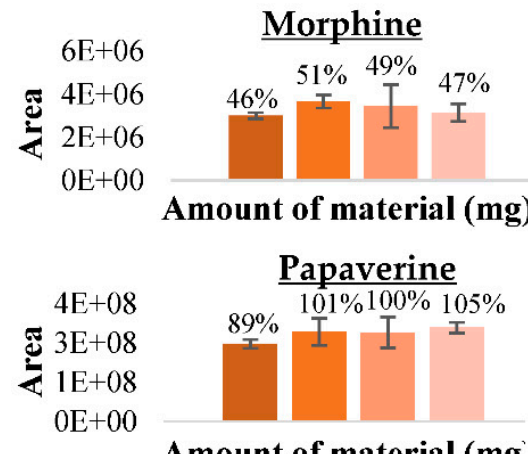

Amount of material (mg

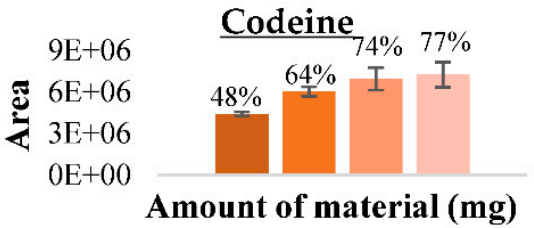

$2 \mathrm{E}+08$
$1 \mathrm{E}+08$
$6 \mathrm{E}+07$
$0 \mathrm{E}+00$
Amount of material (mg)

Noscapine

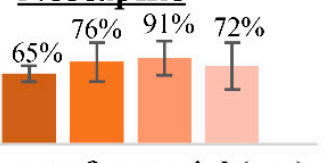

Amount of material (mg)

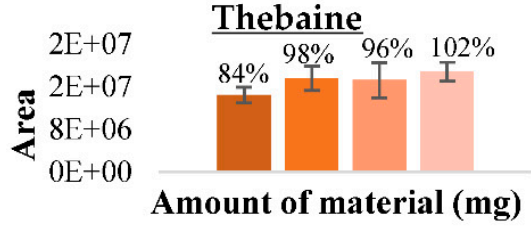

Oripavine

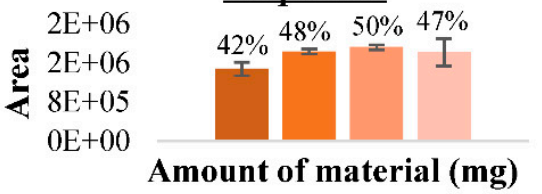

$20 \mathrm{mg} \quad \square 0 \mathrm{mg} \quad \square 7 \mathrm{mg} \quad \square 100 \mathrm{mg}$

Figure 4. Effect of the different amounts of material in the optimised MSPE procedure with $\mathrm{Fe}_{3} \mathrm{O}_{4} @ S \mathrm{O}_{2} @ \mathrm{mSiO}_{2} \mathrm{material}$.

\subsection{Instrumental and Method Validation}

The instrumental validation parameters are displayed in Table S9. First, the linear range of each of the six analytes dissolved in pure solvent was evaluated. Instrumental limits of detection and quantification were calculated by analysing dilutions with decreasing concentration until the S/N ratio was approximately 10 . The LOQ and LOD were estimated as 10 and 3 times the $\mathrm{S} / \mathrm{N}$ ratio, respectively, obtaining the LOQ and LOD for morphine, codeine and oripavine around $8 \times 10^{-2}$ and $2 \times 10^{-2} \mu \mathrm{g} / \mathrm{L}$, respectively, and for thebaine, papaverine and noscapine around $5 \times 10^{-3}$ and $1 \times 10^{-3} \mu \mathrm{g} / \mathrm{L}$, respectively (Table S9). The linear range started at $0.1 \mu \mathrm{g} / \mathrm{L}$ for morphine, codeine and oripavine; or at $0.01 \mu \mathrm{g} / \mathrm{L}$ for thebaine, papaverine and noscapine up to $5000 \mu \mathrm{g} / \mathrm{L}$.

The method validation parameters are displayed in Table 2. The MDL and MQL for morphine, codeine, papaverine and noscapine were 0.07 and $0.24 \mu \mathrm{g} / \mathrm{kg}$; and for thebaine were 0.72 and $2.4 \mu \mathrm{g} / \mathrm{kg}$; and for oripavine were 72.07 and $240 \mu \mathrm{g} / \mathrm{kg}$, respectively. The linear range started at $0.01 \mu \mathrm{g} / \mathrm{L}$ for morphine, codeine, papaverine and noscapine; at $0.1 \mu \mathrm{g} / \mathrm{L}$ for thebaine; or at $10 \mu \mathrm{g} / \mathrm{L}$ for oripavine up to $5000 \mu \mathrm{g} / \mathrm{L}$. Calibration lines were obtained with an adequate $\mathrm{R}^{2}(0.999)$. In addition, the $\mathrm{Cm}$ was calculated, which was always $\geq 92 \%$, successfully accomplishing the criteria established on the guidelines [35].

In order to evaluate the $\mathrm{ME}$, the slopes of each of the calibration lines were compared. As shown in Table 2, the ME (\%) obtained when comparing the slopes of the purified matrix versus the slope of the solvent ranged from $80-109 \%$ for codeine, thebaine and papaverine; thus, these analytes are not affected by any matrix effect that may remain after purification (according to the criteria established in SANTE/11813/2017 [35]). For morphine, noscapine and oripavine, values slightly less than $80 \%$ were obtained, indicating that there was signal suppression. Therefore, to quantify the target analytes in the real samples, matrix-adjusted calibration curves had to be used to compensate for the errors associated with these matrix effects. In addition, a matrix calibration curve without MSPE purification was also analysed and, in this case, the ME (\%) calculated was in almost all analytes more than $120 \%$, especially for thebaine and oripavine, which were 294 and $258 \%$, respectively. For this reason, a considerable improvement was observed after MSPE purification, which allowed the matrix interferences to be reduced. 
Table 2. Validation parameters of the SLE-MSPE-UHPLC-QqQ-MS/MS method for the determination of six opium alkaloids in poppy seeds samples.

\begin{tabular}{|c|c|c|c|c|c|c|c|c|c|c|}
\hline \multirow[b]{2}{*}{ Analytes } & \multirow{2}{*}{$\begin{array}{c}\text { Linear Range } \\
(\mu \mathrm{g} / \mathrm{L})\end{array}$} & \multirow{2}{*}{$\begin{array}{l}\text { Matrix-Matched Calibration } \\
\left(\mathbf{R}^{2}\right)\end{array}$} & \multirow[b]{2}{*}{$\mathrm{Cm}$} & \multirow[b]{2}{*}{ ME } & \multirow[b]{2}{*}{$\operatorname{MDLn}(\mu \mathrm{g} / \mathrm{kg})$} & \multirow[b]{2}{*}{ MQL ( $\mu \mathrm{g} / \mathrm{kg})$} & \multicolumn{2}{|c|}{ Accuracy } & \multicolumn{2}{|c|}{ Precision } \\
\hline & & & & & & & $\begin{array}{l}\text { Recovery } \\
(\% \pm \mathrm{SD})\end{array}$ & $\begin{array}{c}\text { Mean Recovery } \\
(\% \pm \text { SD) }\end{array}$ & $\begin{array}{c}\text { Intra-Day Precision } \\
\text { (RSD \%) }\end{array}$ & $\begin{array}{c}\text { Inter-Day Precision } \\
\text { (RSD \%) }\end{array}$ \\
\hline Morphine & $0.01-5000$ & $y=3269 x+32,452(0.999)$ & 92 & 64 & 0.07 & 0.24 & $\begin{array}{l}50 \pm 1^{\mathrm{a}} \\
42 \pm 2^{\mathrm{b}}\end{array}$ & $46 \pm 2$ & $\begin{array}{l}4^{\mathrm{a}} \\
2^{\mathrm{b}}\end{array}$ & $\begin{array}{l}11^{\mathrm{a}} \\
5^{\mathrm{b}}\end{array}$ \\
\hline Codeine & $0.01-5000$ & $\mathrm{y}=2554 \mathrm{x}+29,642(0.999)$ & 96 & 86 & 0.07 & 0.24 & $\begin{array}{l}64 \pm 2^{\mathrm{a}} \\
71 \pm 6^{\mathrm{b}} \\
\end{array}$ & $68 \pm 4$ & $\begin{array}{l}3^{\mathrm{a}} \\
2^{\mathrm{b}} \\
\end{array}$ & $\begin{array}{l}8^{\mathrm{a}} \\
4^{\mathrm{b}} \\
\end{array}$ \\
\hline Thebaine & $0.1-5000$ & $y=10,093 x+485,953(0.999)$ & 96 & 109 & 0.72 & 2.40 & $\begin{array}{l}72 \pm 3^{\mathrm{a}} \\
76 \pm 4^{\mathrm{b}}\end{array}$ & $74 \pm 4$ & $\begin{array}{l}5^{\mathrm{a}} \\
0^{\mathrm{b}}\end{array}$ & $\begin{array}{l}7^{\mathrm{a}} \\
4^{\mathrm{b}} \\
\end{array}$ \\
\hline Papaverine & $0.01-5000$ & $\mathrm{y}=33,441 \mathrm{x}+2,814,320(0.999)$ & 92 & 80 & 0.07 & 0.24 & $\begin{array}{l}116 \pm 5^{\mathrm{a}} \\
101 \pm 1^{\mathrm{b}}\end{array}$ & $109 \pm 3$ & $\begin{array}{l}5^{\mathrm{a}} \\
2^{\mathrm{b}} \\
\end{array}$ & $\begin{array}{l}9^{\mathrm{a}} \\
7^{\mathrm{b}} \\
\end{array}$ \\
\hline Noscapine & $0.01-5000$ & $\mathrm{y}=42,914 \mathrm{x}+1,631,091(0.999)$ & 94 & 65 & 0.07 & 0.24 & $\begin{array}{l}109 \pm 1^{\mathrm{a}} \\
97 \pm 1^{\mathrm{b}}\end{array}$ & $103 \pm 1$ & $\begin{array}{l}4^{\mathrm{a}} \\
3^{\mathrm{b}}\end{array}$ & $\begin{array}{l}10^{\mathrm{a}} \\
8^{\mathrm{b}} \\
\end{array}$ \\
\hline Oripavine & $10-5000$ & $y=1080 x-31,137(0.999)$ & 94 & 31 & 72.07 & 240 & $\begin{array}{l}51 \pm 3^{\mathrm{a}} \\
53 \pm 3^{\mathrm{b}}\end{array}$ & $52 \pm 3$ & $\begin{array}{l}3^{\mathrm{a}} \\
3^{\mathrm{b}}\end{array}$ & $\begin{array}{l}5^{\mathrm{a}} \\
5^{\mathrm{b}}\end{array}$ \\
\hline
\end{tabular}

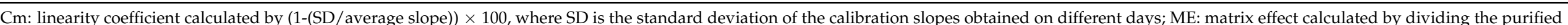

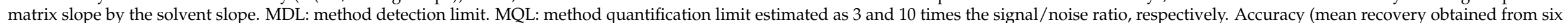

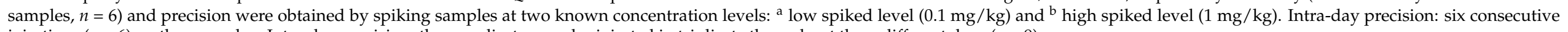
injections $(n=6)$ on the same day; Inter-day precision: three replicate samples injected in triplicate throughout three different days $(n=9)$. 
Accuracy was expressed as the average recovery obtained from six samples $(n=6)$ spiked with the analytes at a known concentration and subjected to the proposed extractionpurification procedure. Accuracy was evaluated at two concentration levels: low $(0.1 \mathrm{mg} / \mathrm{kg})$ and high (1 mg/kg). Recovery values were calculated by comparing the value of the samples with the value of the simulated samples (samples subjected to the same extraction and purification process but spiked at the same concentration level prior to chromatographic analysis). As shown in Table 2, the recovery values obtained were in the range 70-116\%, thus favorable according with the guidelines [35] However, for morphine and oripavine, the recoveries obtained were around $50 \%$, which may be due to the fact that they were the smallest analytes and displayed higher intraparticle diffusion and were, therefore, more difficult to desorb, resulting in lower recoveries. As the molecules were smaller in size, the adsorbent material adsorbed the analytes but they were not completely desorbed as they remained in the internal and smaller pores of the material due to the fact that they are the compounds with the highest intraparticle coefficient (see Section 3.3.3). In order to check that the recovery value of morphine was associated with the nature of the analyte, a recovery assay with morphine-D3 was also performed and a similar recovery value was obtained $(45 \% \pm 1)$. Satisfactory results of precision were obtained at the two concentration levels evaluated because the RSD values obtained were lower than 6 and 11\% for intra-day and inter-day precision, respectively (Table 2). For this reason, morphine and oripavine also could be quantified in real samples using a correction factor. According to SANTE/11813/2017, the recoveries between 30 and $70 \%$ and 120 and $140 \%$ can be acceptable if RSD is $\leq 20 \%$ [35].

A good selectivity of the method was obtained as shown in Figure 5. When comparing the chromatograms and the spectra of each of the analytes, it was found that the variation of the retention time was in all cases $\leq 0.1 \mathrm{~min}$ deviation and the ion ratios of the sample extracts were within $\pm 30 \%$ (relative) of the average of the calibration standards for each of the analytes, which is in accordance with established in the reference guide [35]. All samples showed two peaks to codeine. However, the first peak did not coincide with the retention time of the standard and the ratio of the product ions did not accord. As it did not comply with these two criteria, this first peak was discarded and was considered not to be codeine; instead, it was considered to be a matrix product. In addition, for oripavine, a second peak was also observed in some standards or samples, which was related to thebaine since it appeared in its retention time, and since oripavine is its main metabolite and some of its transitions were similar.

Finally, these results indicated that the proposed method showed good analytical performance and could be successfully used for the extraction, purification by MSPE and quantification of poppy seeds samples.

\subsection{Comparison of the Proposed Methodology with Others Reported Methods}

The developed method was compared with other methods published in recent years for the analysis of opium alkaloids in poppy seeds, straw or capsules and hot pot, a traditional Chinese food. Table 3 summarises the extraction, purification and analytical techniques used and the main characteristics of each methodology. As has been observed, the most used separation technique is HPLC, although there are authors who also use UHPLC because it has the advantage of reducing analysis times. Chromatography times for methods developed with HPLC-MS/MS are between 15 and $30 \mathrm{~min}$ [6,20], while methods developed with UHPLC-MS/MS take between 7 and $10 \mathrm{~min}$ [1,22]. A noteworthy aspect of this proposed method is that only 5 min were sufficient to efficiently quantify the six opium alkaloids, which is considerably less time than the methods already developed to quantify opioids in the literature. This is very important since reducing the analysis time also reduces the cost. In addition, the detector that has been mainly used is the QqQ, which means a much more selective detection with higher sensitivity, although there are some studies with other detectors, such as DAD or UV detector $[16,24]$. 


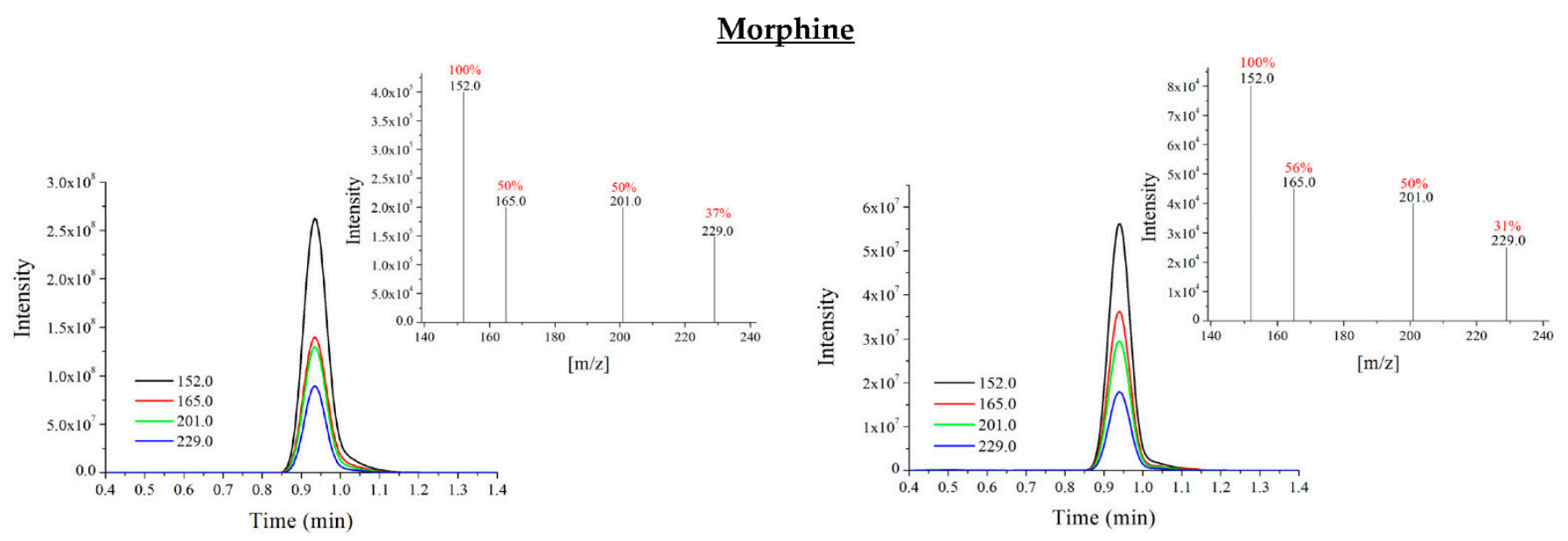

\section{Codeine}
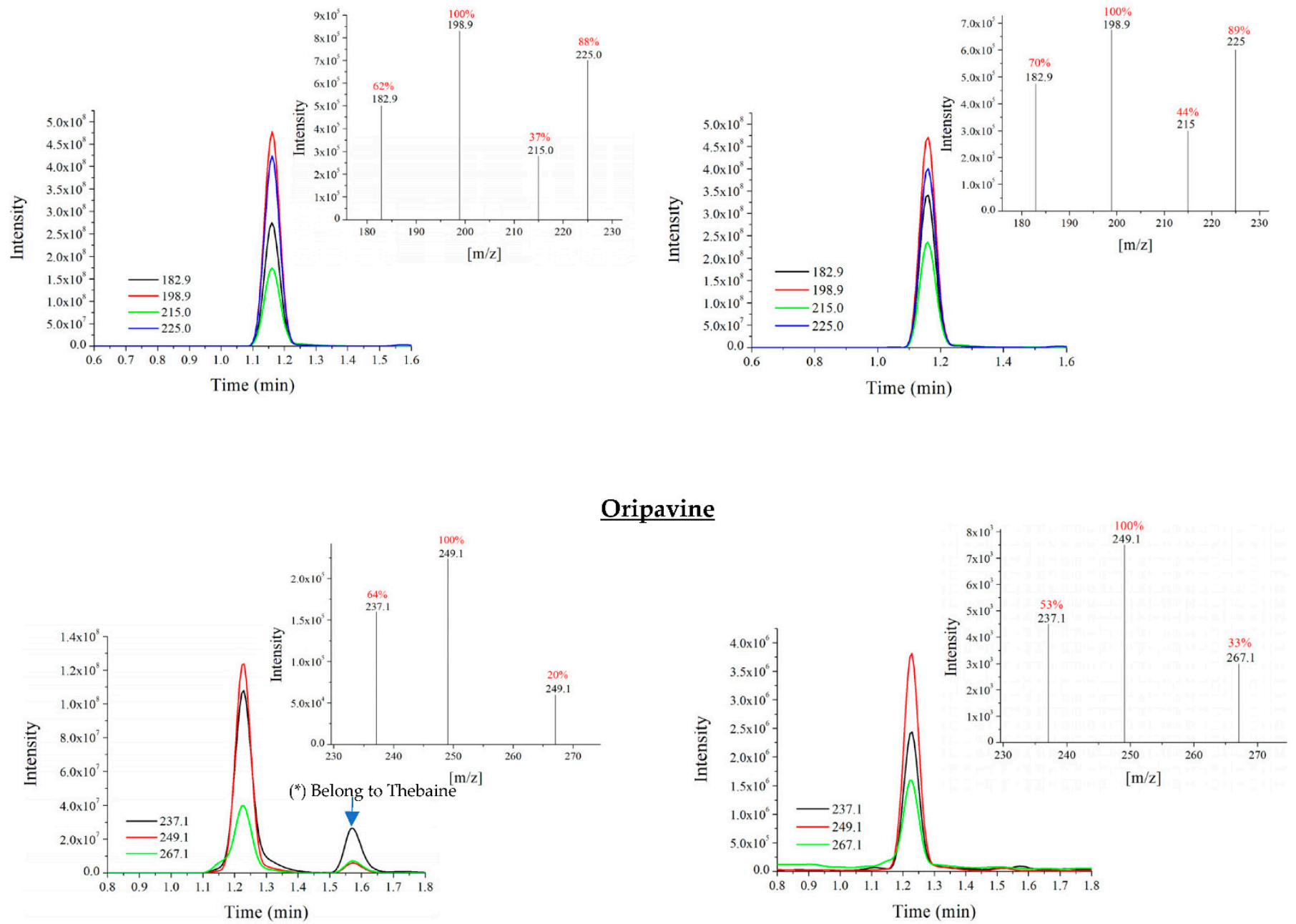

Figure 5. Cont. 


\section{Thebaine}
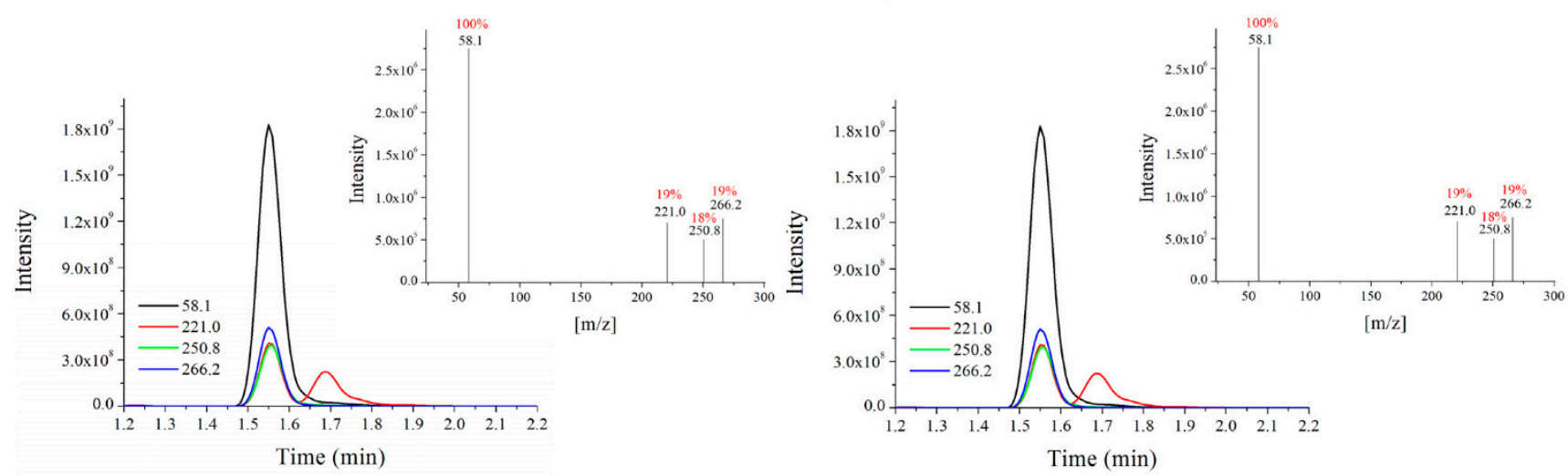

\section{Papaverine}
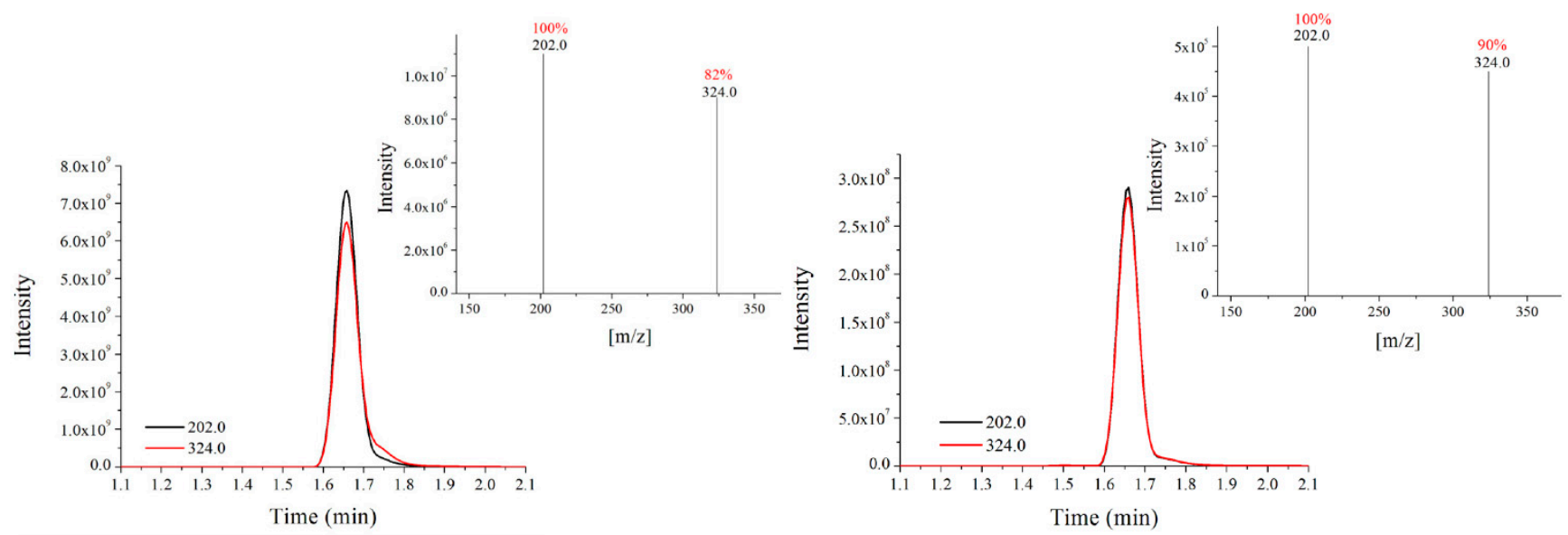

\section{Noscapine}
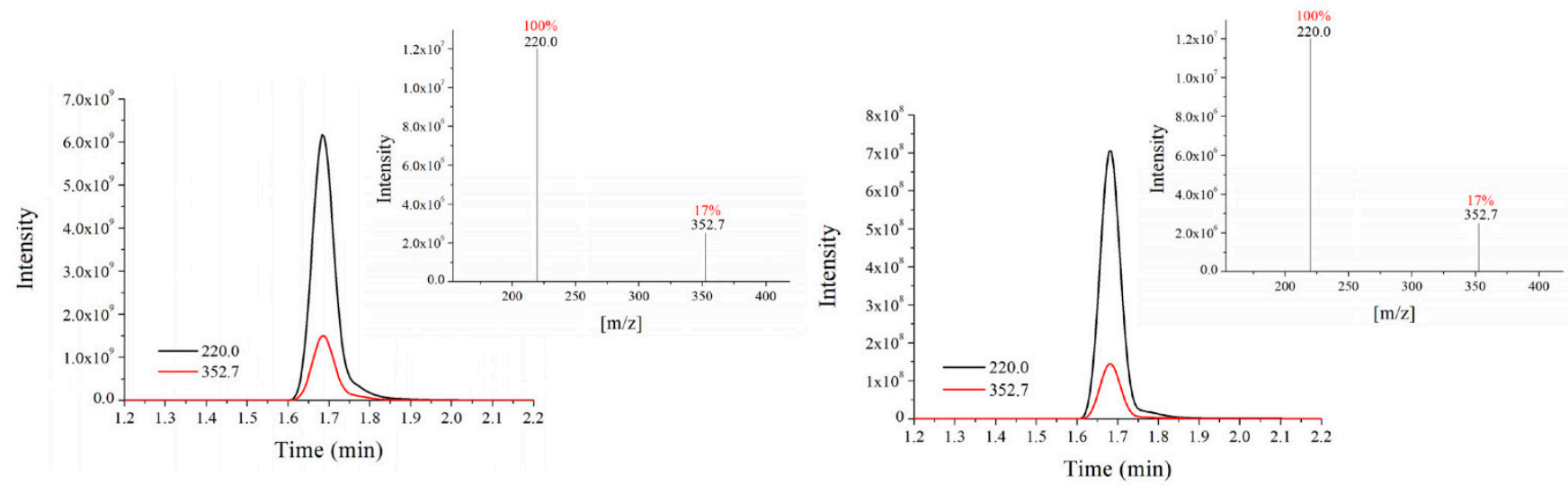

Figure 5. Comparison between the extracted ions chromatograms and the intensity of fragment ions mass spectrum (relative abundance (\%) in colour red) obtained for each of the compounds in a standard solution mixture $1 \mathrm{mg} / \mathrm{L}$ (left) with respect to a poppy seed sample (right). 


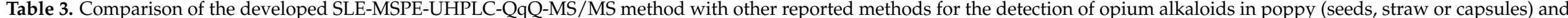
hot pot.

\begin{tabular}{|c|c|c|c|c|c|c|c|c|c|}
\hline \multirow{2}{*}{ Sample } & \multirow{2}{*}{ Analytes } & \multicolumn{2}{|c|}{ Sample Treatment } & \multirow{2}{*}{ Analysis Technique } & \multirow{2}{*}{ MDL $(\mu \mathrm{g} / \mathrm{kg})$} & \multirow{2}{*}{$\operatorname{MQL}(\mu \mathrm{g} / \mathrm{kg})$} & \multirow{2}{*}{ Recovery (\%) } & \multirow{2}{*}{ RSD (\%) } & \multirow{2}{*}{ Ref. } \\
\hline & & Extraction & Purification & & & & & & \\
\hline Poppy seeds & $\begin{array}{l}\text { MOR, COD, THEB, } \\
\text { NOS, PAP }\end{array}$ & $\begin{array}{c}\text { AcN/water/formic acid, } \\
80 / 19 / 1, v / v / v(100 \mathrm{~mL} \\
30 \mathrm{~min}, \times 2)\end{array}$ & - & $\begin{array}{l}\text { UHPLC-QqQ- } \\
\text { MS/MS }\end{array}$ & - & 100 & $77-172$ & $<20.0$ & [1] \\
\hline $\begin{array}{l}\text { Poppy seeds, } \\
\text { cake, buns }\end{array}$ & $\begin{array}{l}\text { MOR, COD, } \\
\text { PAP, NOS }\end{array}$ & $\begin{array}{l}\mathrm{MeOH} 0.1 \% \text { acetic acid }(30 \mathrm{~mL} \\
60 \mathrm{~min})\end{array}$ & - & HPLC-QqQ-MS/MS & $70-300$ & $200-1000$ & - & $7.4-9.0$ & [6] \\
\hline Poppy straw & $\begin{array}{l}\text { MOR, COD, } \\
\text { THEB, PAP }\end{array}$ & $\mathrm{MeOH}(5 \mathrm{~mL}, 20 \mathrm{~min}, \times 2)$ & - & HPLC-DAD & $200-1800$ & $600-5400$ & $97-99$ & $0.2-0.4$ & {$[17]$} \\
\hline Hot pot & $\begin{array}{l}\text { MOR, COD, THEB, } \\
\text { PAP, NOS }\end{array}$ & $\begin{array}{c}\mathrm{HCl} 0.1 \mathrm{M}(20 \mathrm{~mL}, 10 \mathrm{~min}) \text { and } \\
\mathrm{PE}(10 \mathrm{~mL})\end{array}$ & SPE (Oasis MCX 60 mg) & $\begin{array}{l}\text { UHPLC-QqQ- } \\
\text { MS/MS }\end{array}$ & $0.003-0.04$ & $0.01-0.1$ & $72-124$ & $7.9-23.7$ & [19] \\
\hline Poppy straw & $\begin{array}{l}\text { MOR, COD, } \\
\text { THEB, PAP }\end{array}$ & Water $5 \%$ acetic acid & SPE (Oasis MCX) & $\begin{array}{l}\text { HPLC- Ion } \\
\text { trap-MS/MS }\end{array}$ & $400-17,500$ & $1100-52,200$ & - & - & [20] \\
\hline Hot pot & $\begin{array}{l}\text { MOR, COD, THEB, } \\
\text { PAP, NOS }\end{array}$ & Water/AcN 50\% (20 mg, $5 \mathrm{~min})$ & $\begin{array}{c}\mathrm{MSPE} \\
\left(\mathrm{Fe}_{3} \mathrm{O}_{4} @ \mathrm{SiO}_{2} @ A D M E\right. \\
50 \mathrm{mg})\end{array}$ & $\begin{array}{l}\text { HPLC-QqQLIT- } \\
\text { MS/MS }\end{array}$ & $0.05-0.8$ & $0.25-2.5$ & $80-115$ & $4.3-10.7$ & [22] \\
\hline Hot pot & $\begin{array}{l}\text { MOR, COD, THEB, } \\
\text { PAP, NAR }\end{array}$ & $\begin{array}{l}\mathrm{AcN} 0.1 \% \text { formic acid } \\
\text { and n-hexane }\end{array}$ & $\begin{array}{c}\mathrm{MSPE} \\
\left(\mathrm{Fe}_{3} \mathrm{O}_{4} @ \mathrm{SiO}_{2} @ \mathrm{CS} / \mathrm{GO}\right. \\
15 \mathrm{mg})\end{array}$ & $\begin{array}{c}\text { UHPLC- } \\
\text { QqQLIT-MS/MS }\end{array}$ & $0.016-0.092$ & $0.036-0.31$ & $75-104$ & $0.7-9.5$ & [23] \\
\hline Poppy capsules & NAR, PAP & SFE & $\begin{array}{c}\text { MSPE }\left(\mathrm{Fe}_{3} \mathrm{O}_{4} @ \mathrm{Cu} @ \mathrm{DPTC}\right. \\
50 \mathrm{mg})\end{array}$ & HPLC-UV & $1-100$ & - & $88-99$ & $5.8-7.7$ & [25] \\
\hline
\end{tabular}

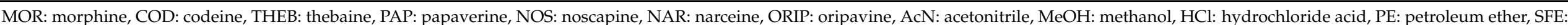

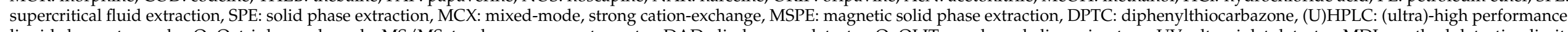

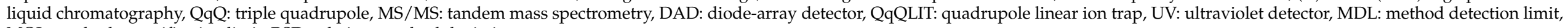
MQL: method quantification limit, RSD: relative standard deviation. 
As can be seen in Table 3, the main extraction technique used in the literature is SLE with organic solvents (acetonitrile/water/formic acid, acidified methanol or pure methanol) $[1,6,17]$. The main disadvantage of these methods is the high consumption of organic solvents, which is about $200 \mathrm{~mL}$. This is a very important aspect to consider as they are damaging to the environment. In addition, although it provides some good recovery results, it can result in incorrect results due to matrix interferences, as seen in this work and the comments of some of the authors in their works [1]. Furthermore, it should be considered that since there are so many impurities that have not been removed, the chromatographic column and the instrument become dirty more easily, which shortens its life of use. Therefore, it is very important to perform a purification step that can remove these matrix interferences. The conventional purification technique and which two authors use with these analytes is SPE $[19,20]$. However, it is a very complex technique to operate compared to other new purification techniques, such as MSPE, because it avoids the strict control of the loading and elution flow rate and obstruction problems. There are still few authors who have started to use magnetic adsorbent materials to purify samples to quantify opioids and none of them uses it for poppy seeds samples. Three have been found in the literature, although one of them only analyses two of the main opioids. In all of them, minimisation of matrix interferences and good recoveries has been obtained by selectively adsorbing the analytes. However, in the methodology proposed in this work, lower MDL and MQL have been obtained than in other published works (between $0.07-72.01 \mu \mathrm{g} / \mathrm{kg}$ and $0.24-240 \mu \mathrm{g} / \mathrm{kg}$, respectively). In addition, the advantage of this method over others is that purification is completed in only $4 \mathrm{~min}$ ( $1 \mathrm{~min}$ of adsorption and $3 \mathrm{~min}$ of desorption), unlike others that take up to $30 \mathrm{~min}$ [23]. Moreover, it is the first methodology developed and validated for the quantification of the six main opium alkaloids in poppy seeds, which is very important to take into account since EFSA claimed, in its last opinion in 2018, that there was an absence of studies with all these analytes and, therefore, there is a need to develop methodologies capable of quantifying all of them [15]. The result is that this method is completely able, in a quick, easy and efficient manner, to quantify the six target analytes in poppy seed samples.

\subsection{Application of the Method SLE-MSPE-UHPLC-QqQ-MS/MS to Real Samples of Poppy Seeds}

Finally, the method was applied to analyse 16 seeds samples: 11 commercial poppy seeds, 2 wild poppy seeds and 3 commercial edible seeds mix (Table S1). Once the areas of each of the samples were obtained, the corresponding recovery values (Table 2) were applied and these results were divided by the areas obtained from the internal standard (morphine-D3). Finally, they were interpolated into matrix-matched calibration curves with morphine-D3 to minimise the possible signal errors and to produce more accurate results.

All samples were found to contain the six opium alkaloids (Table 4) and so they were contaminated by latex from the Papaver somniferum L. plant. This result was very surprising because three of them were labelled as being from Papaver rhoeas L. species, which does not contain opium alkaloids (samples PS03, PS05 and PS06). Moreover, physically, they look similar to the blue poppy seeds of the Papaver somniferum L. species. Therefore, these two aspects provided enough evidence to assert that there was incorrect labelling of these products. For comparison, wild corn poppy seeds (PS10), which were black and small, were analysed and none of the analytes was detected, whereas in wild opium poppy seeds (PS9), the six target analytes were found. This confirms the theory that the common poppy (Papaver rhoeas L.) does not contain opium alkaloids and the labels of the commercial products analysed were incorrect. 
Table 4. Range of occurrence $(\mathrm{mg} / \mathrm{kg})$ of each of the six opium alkaloids analysed in three samples $(n=3)$.

\begin{tabular}{|c|c|c|c|c|c|c|}
\hline Code & Morphine & Codeine & Thebaine & Papaverine & Noscapine & Oripavine \\
\hline PS01 & $20.6-45.4$ & $5.7-19.2$ & <MQL-7.3 & $7.3-19.5$ & $9.4-24.8$ & $<\mathrm{MQL}-0.6$ \\
\hline PS02 & 23.2-118.7 & $3.2-26.7$ & $0.9-17.7$ & $2.1-27.1$ & $6.5-42.6$ & $3.8-22.9$ \\
\hline PS03 & $154.9-249.0$ & $21.3-45.8$ & $12.4-31.5$ & $0.8-2.9$ & $0.3-108.7$ & $9.8-33.4$ \\
\hline PS04 & 17.0-19.5 & $1.0-1.9$ & $3.4-6.5$ & $<\mathrm{MQL}$ & $<\mathrm{MQL}$ & $<\mathrm{MQL}$ \\
\hline PS05 & $1.9-2.2$ & $<\mathrm{MQL}$ & $<\mathrm{MQL}$ & $<\mathrm{MQL}$ & $<\mathrm{MQL}$ & $<\mathrm{MQL}$ \\
\hline PS06 & $1.5-3.7$ & $<\mathrm{MQL}$ & $<\mathrm{MQL}$ & $<\mathrm{MQL}$ & $<\mathrm{MQL}$ & $<\mathrm{MQL}$ \\
\hline PS07 & $6.9-59.3$ & $0.4-0.9$ & $<$ MQL-5.8 & <MQL-1.1 & $0.7-36.3$ & $<$ MQL-0.8 \\
\hline PS08 & $28.8-35.1$ & $3.4-4.0$ & $0.8-3.4$ & $10.5-19.9$ & $18.1-22.7$ & $<\mathrm{MQL}$ \\
\hline PS09 & $58.6-64.3$ & $2.9-3.6$ & $1.3-3.2$ & $<\mathrm{MQL}$ & $19.0-21.7$ & $<\mathrm{MQL}$ \\
\hline PS10 & ND & ND & ND & ND & ND & ND \\
\hline PS11 & $33.7-53.0$ & $3.7-8.7$ & $37.4-136.2$ & $<$ MQL-1.9 & $2.0-21.1$ & $2.3-13.8$ \\
\hline PS12 & $4.1-22.3$ & <MQL-0.3 & <MQL-1.5 & $<\mathrm{MQL}$ & $<\mathrm{MQL}$ & <MQL-0.5 \\
\hline PS13 & $49.6-125.4$ & $2.3-16.5$ & $3.9-15.6$ & $<\mathrm{MQL}$ & $<\mathrm{MQL}$ & <MQL-0.5 \\
\hline MIX1 & $6.5-8.7$ & $<$ MQL-0.04 & $<\mathrm{MQL}$ & $<\mathrm{MQL}$ & $<\mathrm{MQL}$ & $<\mathrm{MQL}$ \\
\hline MIX2 & $44.0-54.0$ & $0.7-3.0$ & $0.68-2.6$ & $<\mathrm{MQL}$ & $<\mathrm{MQL}$ & <MQL-0.3 \\
\hline MIX3 & $7.0-8.6$ & $<\mathrm{MQL}$ & $<\mathrm{MQL}$ & $<\mathrm{MQL}$ & $<\mathrm{MQL}$ & $<\mathrm{MQL}$ \\
\hline
\end{tabular}

MQL: method quantification limit (for codeine, papaverine and noscapine: $0.24 \mu \mathrm{g} / \mathrm{kg}$; for thebaine: $2.40 \mu \mathrm{g} / \mathrm{kg}$; and for oripavine: $240 \mu \mathrm{g} / \mathrm{kg}$ ). ND: not detected. To quantify seed samples, matrix-matched calibration was used with internal standard (morphine: $y=0.006 x-0.182$; codeine: $y=0.005 x+0.117$; thebaine: $y=0.020 x+1.853$; papaverine: $y=0.069 x+6.739 ;$ noscapine: $y=0.080 x+6.049$; oripavine: $\mathrm{y}=0.002 \mathrm{x}+0.009)$.

In addition, the concentrations of each type of poppy seed were calculated. Due to the surface contamination and the large number of other factors influencing the concentration of these alkaloids in poppy seeds, variable amounts have been found in the same batch of seeds. For these reasons, the range of concentration is provided to show the extent of the variation and is in accordance with other researchers who identified a variation in opium alkaloids within a batch and between batches of poppy seeds analysed $[1,2,44]$. Concentrations of morphine ranged from 1.5 to $249.0 \mathrm{mg} / \mathrm{kg}$, codeine from $<0.2 \mu \mathrm{gg} / \mathrm{kg}$ to $45.8 \mathrm{mg} / \mathrm{kg}$, thebaine from $<2.4 \mu \mathrm{g} / \mathrm{kg}$ to $136.2 \mathrm{mg} / \mathrm{kg}$, papaverine from $<0.2 \mu \mathrm{g} / \mathrm{kg}$ to $27.1 \mathrm{mg} / \mathrm{kg}$, noscapine from $<0.2 \mu \mathrm{g} / \mathrm{kg}$ to $108.7 \mathrm{mg} / \mathrm{kg}$ and oripavine from $<240 \mu \mathrm{g} / \mathrm{kg}$ to $33.4 \mathrm{mg} / \mathrm{kg}$. The opium alkaloid concentrations obtained in poppy seeds agreed with concentrations determined by other researchers. In the case of morphine, wide ranges of concentrations were obtained by López et al.; $0.2-241 \mathrm{mg} / \mathrm{kg}$, Sproll et al.; between $<1$ and $270 \mathrm{mg} / \mathrm{kg}$, Bjerver et al. who found $2.6-106.7 \mathrm{mg} / \mathrm{kg}$; and Hayes et al. between 17 and $294 \mathrm{mg} / \mathrm{kg}[1,6,45,46]$. Lower results were found by Carlin et al. between 3 and $64 \mathrm{mg} / \mathrm{kg}$ [44] and higher levels were found by Powers et al. from <1 to $2788 \mathrm{mg} / \mathrm{kg}$ [3]. Regarding codeine, the results obtained were very similar to the results obtained by Sproll et al., who found $<0.3-56 \mathrm{mg} / \mathrm{kg}$ [6] but were lower than the results found by López et al. who found from $<0.1$ to $348 \mathrm{mg} / \mathrm{kg}$ and Powers et al. from $<1$ to $247.6 \mathrm{mg} / \mathrm{kg}[1,3]$. On the other hand, the results obtained for thebaine were similar to those of López et al., as they found $<0.1-106 \mathrm{mg} / \mathrm{kg}$ and Powers et al. from $<1$ to $124 \mathrm{mg} / \mathrm{kg}$ [1,3]. Regarding papaverine and noscapine, the contents found in this study were higher than others, as Sproll et al. did not detect their presence in any of their samples [6] and López et al. only determined $<0.1-3.8 \mathrm{mg} / \mathrm{kg}$ of papaverine and $<0.1-5 \mathrm{mg} / \mathrm{kg}$ of noscapine [1]. Notably, oripavine had not been previously analysed in poppy seeds by any author.

In addition, many of the samples showed values below the MQL but in all of them considerably high values of morphine were quantified, which meant that all samples except two (87\%) exceeded the maximum limit established by Germany ( $4 \mathrm{mg} / \mathrm{kg}$ ) and the $73 \%$ exceeded the reference level established in the EU $(10 \mathrm{mg} / \mathrm{kg}$ morphine in poppy seeds for direct human consumption). It therefore implies that this agreement is not being fulfilled. In addition, $73 \%$ exceeded the Hungarian limit for morphine (30 mg/kg). For the other analytes, the maximum limit established by Hungary was $20 \mathrm{mg} / \mathrm{kg}$, so two samples exceeded the maximum limit for codeine (PS02 and PS03), two samples for thebaine (PS03 and PS11), three for papaverine (PS01, PS02 and PS09) and seven for noscapine (PS01, PS02, 
PS03, PS07, PS08, PS09 and PS11). If oripavine with the same concentration was considered, two samples would exceed this limit (PS02 and PS03). As it can be seen in Table 4, three seed mixes consisting of sunflower, sesame, brown flax, pumpkin and poppy seeds were also analysed. In one of them (MIX2), a considerably high amount of morphine was found $(54 \mathrm{mg} / \mathrm{kg})$, taking into account that only $5-10 \%$ of the seeds in the mix were poppy seeds. Therefore, poppy seeds used in MIX2 also exceeded the limit maximum established in the EU. All these results confirm the current problems with the marketing of such products in the EU because, in the absence of common legislation, a high number of RASFF health alerts are occurring, some 30 notifications since 2005 [4].

Considering the highest concentration obtained in each of the batches as shown in Figure 6, the samples with the highest number of total opiate alkaloids are PS03, with approximately $475 \mathrm{mg} / \mathrm{kg}$ (supposedly of the Papaver rhoeas L. species) and PSO2 with approximately $250 \mathrm{mg} / \mathrm{kg}$ (physically blue poppy seed from Turkey). Especially high was the amount of thebaine found in PS11 (physically blue poppy seed from Czech Republic). Oripavine was found in all the commercial samples.

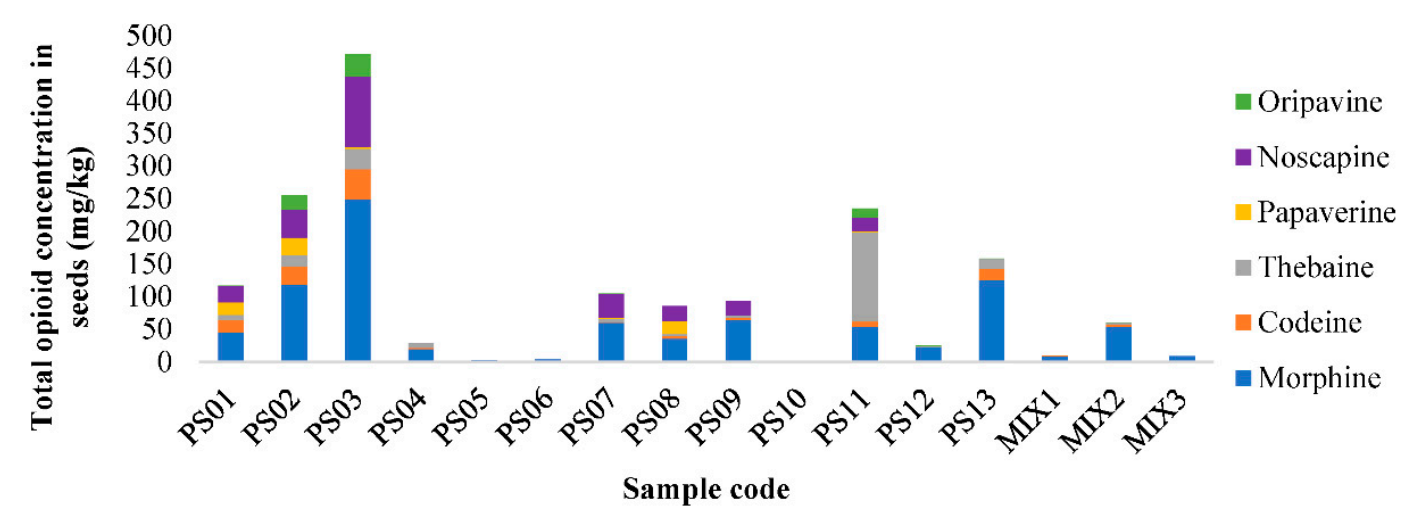

Figure 6. Total content of opium alkaloids found in poppy seeds and seed mixes analysed by the SLE-MSPE-UHPLC-QqQMS/MS method proposed.

\section{Conclusions}

A rapid, simple and efficient method was developed for the prior determination of morphine, codeine, thebaine, papaverine, noscapine and oripavine in poppy seeds by ultrahigh-performance liquid chromatography-tandem mass spectrometry. Mesostructured silica-coated magnetic nanoparticles were used as adsorbent for MSPE and the sample extracts were purified in just $4 \mathrm{~min}$. Furthermore, the chromatographic method was only $5 \mathrm{~min}$ long, which is very fast and considerably reduces the time and therefore the cost of the analysis. The method was successfully applied to the analysis of commercial poppy seed samples and seed mixes purchased in Spanish supermarkets at the end of 2020. The most surprising result was that incorrect labelling is occurring and so the correct naming of the seeds used is necessary. The six opium alkaloids were found in all the commercial samples analysed and 73\% exceeded the reference level for morphine in poppy seeds for direct human consumption established in the EU $(<10 \mathrm{mg} / \mathrm{kg})$. All these results confirmed the need to further study the actual exposure to opioid alkaloids of the population by examining not only the consumption of poppy seeds but also other foods containing poppy seeds in order to establish harmonised legislation in all EU members and thus facilitate the common market by decreasing the number of RASFF alerts.

Supplementary Materials: The following are available online at https: / www.mdpi.com/article/ 10.3390/foods10071587/s1, Section S1.1: Instrumental and Method Validation, Figure S1: SEM images of $\mathrm{Fe}_{3} \mathrm{O}_{4}(\mathbf{a}), \mathrm{Fe}_{3} \mathrm{O}_{4} @ \mathrm{SiO}_{2}(\mathbf{b})$ and $\mathrm{Fe}_{3} \mathrm{O}_{4} @ \mathrm{SiO}_{2} @ \mathrm{mSiO}_{2}$ (c) magnetic particles, Figure S2: XRD patterns of at low angles (a) and wide angles (b): $\mathrm{Fe}_{3} \mathrm{O}_{4}(1), \mathrm{Fe}_{3} \mathrm{O}_{4} @ \mathrm{SiO}_{2}(2), \mathrm{Fe}_{3} \mathrm{O}_{4} @ \mathrm{SiO}_{2} @ \mathrm{C}_{8}$ (3), $\mathrm{Fe}_{3} \mathrm{O}_{4} @ \mathrm{SiO}_{2} @ \mathrm{C}_{18}(4), \mathrm{Fe}_{3} \mathrm{O}_{4} @ \mathrm{SiO}_{2} @ \mathrm{mSiO}_{2}(5), \mathrm{Fe}_{3} \mathrm{O}_{4} @ \mathrm{SiO}_{2} @ \mathrm{mSiO}_{2} @ \mathrm{C}_{8}(6)$ and $\mathrm{Fe}_{3} \mathrm{O}_{4} @ \mathrm{SiO}_{2} @ \mathrm{mSiO}_{2}$ 
$@ \mathrm{C}_{18}$ (7), Figure S3: FT-IR spectra of particles with different treatment to remove the surfactant (a): calcination treatment $\mathrm{Fe} 3 \mathrm{O} 4 @ \mathrm{SiO}_{2} @ \mathrm{mSiO}_{2}(1)$ and particles after treatment with acetone extraction $\mathrm{Fe}_{3} \mathrm{O}_{4} @ \mathrm{SiO}_{2} @ \mathrm{CTAB} / \mathrm{mSiO}_{2}$ (2). FT-IR spectra of 7 synthesised materials (b): $\mathrm{Fe}_{3} \mathrm{O}_{4}(1), \mathrm{Fe}_{3} \mathrm{O}_{4} @ \mathrm{SiO}_{2}$ (2), $\mathrm{Fe}_{3} \mathrm{O}_{4} @ \mathrm{SiO}_{2} @ \mathrm{mSiO}_{2}(3), \mathrm{Fe}_{3} \mathrm{O}_{4} @ \mathrm{SiO}_{2} @ \mathrm{C}_{8}(4), \mathrm{Fe}_{3} \mathrm{O}_{4} @ \mathrm{SiO}_{2} @ \mathrm{C}_{18}$ (5), $\mathrm{Fe}_{3} \mathrm{O}_{4} @ \mathrm{SiO}_{2} @ \mathrm{mSiO}_{2} @ \mathrm{C}_{8}$ (6) and $\mathrm{Fe}_{3} \mathrm{O}_{4} @ S \mathrm{SiO}_{2} @ \mathrm{mSiO}_{2} @ \mathrm{C}_{18}$ (7), Figure S4: Image of the first three washes of the $\mathrm{Fe}_{3} \mathrm{O}_{4} @ S_{2} \mathrm{SiO}_{2} @$ $\mathrm{mSiO}_{2}$ material by magnetic decantation, Figure S5: $\mathrm{N}_{2}$ adsorption-desorption isotherms $(\mathbf{a}, \mathbf{c})$ and pore-size distribution (b,d) of $\mathrm{Fe}_{3} \mathrm{O}_{4} @ \mathrm{SiO}_{2}$ and $\mathrm{Fe}_{3} \mathrm{O}_{4} @ \mathrm{SiO}_{2} @ \mathrm{mSiO}_{2}$, respectively, before and after the modification with $\mathrm{C}_{8}$ and $\mathrm{C}_{18}$ ligands, Figure S6: Extracted areas of target analytes in $2.5 \mathrm{~g}$ poppy seeds and $10 \mathrm{~mL}$ of solvent during $10 \mathrm{~min}$ under each of the extraction conditions to be optimised (extraction solvent and agitation type), Figure S7: Extracted areas of the six target analytes in $2.5 \mathrm{~g}$ of poppy seeds with methanol/water 50/50 $(\mathrm{v} / \mathrm{v})$ and magnetic stirring under each of the double extraction conditions (volume and time), Figure S8: Extracted areas of the six target analytes in $2.5 \mathrm{~g}$ of poppy seeds with methanol/water 50/50 (v/v), magnetic stirring and double extraction of $30 \mathrm{~mL}$ for $30 \mathrm{~min}$ under each of the solvent $\mathrm{pH}$ values, Figure S9: Adsorption kinetic (a) and isotherm (b) experiments of six opium alkaloids with $100 \mathrm{mg} \mathrm{Fe} 3 \mathrm{O}_{4} @ \mathrm{SiO}_{2} @ \mathrm{mSiO}_{2} \mathrm{material}_{\text {, }}$ Figure S10: Three kinetics models (a) and two isotherm models (b) for the adsorption of six opium alkaloids on the $\mathrm{Fe}_{3} \mathrm{O}_{4} @ \mathrm{SiO}_{2} @ \mathrm{mSiO}_{2}$, Figure S11: Effect of the solvent $\mathrm{pH}$ value in the adsorption step in methanol/water 50/50 (v/v) with 100 mg of $\mathrm{Fe}_{3} \mathrm{O}_{4} @ \mathrm{SiO}_{2} @ \mathrm{mSiO}_{2}$ material for 1 min, Table S1: Registration of the different poppy seed samples used with their description, species and origin, Table S2: Optimal parameters of MRM for the analysis of each opium alkaloids by UHPLC-QqQMS/MS: precursor and fragment ions, cone voltage (CV), collision energy (CE) and retention time (Rt) of each opium alkaloid, Table S3: Equations of adsorption kinetic and isotherm, Table S4: Kinetic parameters of the adsorption of six opioid alkaloids with 100 mg Fe $\mathrm{F}_{4} @ \mathrm{SiO}_{2} @ \mathrm{mSiO}_{2} \mathrm{material}$ for different times (1-20 min) based on different kinetic models, Table S5: Recovery values (\%) \pm standard deviation (SD) obtained in the MSPE procedure with the solvents used in the SLE of poppy seeds at different desorption times (1, 5, 10 and $20 \mathrm{~min})$, Table S6: Recovery values (\%) \pm standard deviation (SD) obtained in MSPE procedure with eight desorption solvents at different $\mathrm{pH}$ values (non-modified, acid with $1 \%$ formic acid, basic with $1 \%$ ammonia and basic with $10 \%$ ammonia), Table S7: Recovery values (\%) \pm standard deviation (SD) obtained in the MSPE procedure with the mixture of the solvents that showed the best results in desorption step with different proportions $(50 / 50,80 / 20$ and $20 / 80, v / v)$, all of them at basic $\mathrm{pH}$ with solvent/ammonia, 90/10 v/v, Table S8: Recovery values $(\%) \pm$ standard deviation (SD) obtained in MSPE procedure after a different number of consecutive desorptions with diethyl ether/methanol, 80/20, v/v, with $10 \%$ ammonia at $1 \mathrm{~min}$, Table S9: Instrumental validation parameters (solvent linearity, solvent calibration, LOQ and LOD).

Author Contributions: Conceptualization, I.S., S.M.-Z. and D.P.-Q.; methodology, G.C.-H.; validation, G.C.-H. and S.M.-Z.; formal analysis, G.C.-H.; investigation, I.S., S.M.-Z. and D.P.-Q.; resources, G.C.-H.; data curation, G.C.-H.; writing—original draft preparation, I.S., S.M.-Z. and G.C.-H.; writing-review and editing, I.S., S.M.-Z., D.P.-Q. and G.C.-H.; supervision, I.S., S.M.-Z. and D.P.-Q.; project administration, S.M.-Z.; funding acquisition, I.S. All authors have read and agreed to the published version of the manuscript.

Funding: This research was funded by MCIU/AEI/FEDER, UE for project RTI2018-094558-B-I00.

Conflicts of Interest: The authors declare no conflict of interest. The funders had no role in the design of the study; in the collection, analyses or interpretation of data; in the writing of the manuscript or in the decision to publish the results.

\section{References}

1. López, P.; Fauw, D.P.P.-D.; Mulder, P.P.; Spanjer, M.; de Stoppelaar, J.; Mol, H.G.; de Nijs, M. Straightforward analytical method to determine opium alkaloids in poppy seeds and bakery products. Food Chem. 2018, 242, 443-450. [CrossRef]

2. Meos, A.; Saks, L.; Raal, A. Content of alkaloids in ornamental Papaver somniferum L. cultivars growing in Estonia. Proc. Est. Acad. Sci. 2017, 66, 34. [CrossRef]

3. Powers, D.; Erickson, S.; Swortwood, M.J. Quantification of Morphine, Codeine, and Thebaine in Home-Brewed Poppy Seed Tea by LC-MS/MS. J. Forensic Sci. 2018, 63, 1229-1235. [CrossRef]

4. Casado-Hidalgo, G.; Morante-Zarcero, S.; Pérez-Quintanilla, D.; Sierra, I. Opium alkaloids in food products: Current and future perspectives. Trends Food Sci. Technol. 2021, 108, 92-102. [CrossRef] 
5. AESAN. Spanish Food Safety and Nutrition Agency. Opium Alkaloids in Poppy Seeds. 2020. Available online: http://www. aecosan.msssi.gob.es/AECOSAN/docs/documentos/seguridad_alimentaria/gestion_riesgos/opio_semillas_adormidera.pdf (accessed on 23 January 2020).

6. Sproll, C.; Perz, R.C.; Lachenmeier, D.W. Optimized LC/MS/MS analysis of morphine and codeine in poppy seed and evaluation of their fate during food processing as a basis for risk analysis. J. Agric. Food Chem. 2006, 54, 5292-5298. [CrossRef] [PubMed]

7. Moeller, M.R.; Hammer, K.; Engel, O. Poppy seed consumption and toxicological analysis of blood and urine samples. Forensic Sci. Int. 2004, 143, 183-186. [CrossRef]

8. Newmeyer, M.; Concheiro, M.; da Costa, J.L.; LoDico, C.; Gorelick, D.A.; Huestis, M.A. Simultaneous plasma and oral fluid morphine and codeine concentrations after controlled administration of poppy seeds with known opiate content. Forensic Toxicol. 2015, 33, 235-243. [CrossRef]

9. Özbunar, E.; Aydoğdu, M.; Döğer, R.; Bostanc1, H.I.; Koruyucu, M.; Akgür, S.A. Morphine concentrations in human urine following poppy seed paste consumption. Forensic Sci. Int. 2019, 295, 121-127. [CrossRef] [PubMed]

10. Rohrig, T.P.; Moore, C. The determination of morphine in urine and oral fluid following ingestion of poppy seeds. J. Anal. Toxicol. 2003, 27, 449-452. [CrossRef]

11. European Food Safety Authority. Scientific Opinion on the risks for public health related to the presence of opium alkaloids in poppy seeds, EFSA Panel on Contaminants in the Food Chain (CONTAM). EFSA J. 2011, 9, 150. [CrossRef]

12. BfR Recommends Provisional Daily Upper Intake Level and Guidance Value for Morphine in Poppy Seeds, BfR Heath Assessment No. 0.12/2006. 27 December 2005. Available online: https://mobil.bfr.bund.de/cm/349/bfr_recommends_provisional_daily_ upper_intake_level_and_a_guidance_value_for_morphine_in_poppy_seeds.pdf (accessed on 23 January 2020).

13. European Commision, Health and Food Safety Directorate-General, Summary Report of the Standing Committee on Plants, Animals, Food and Feed Held in Brussels on 25 November 2016. Available online: https://ec.europa.eu/food/sites/food/files/ safety/docs/reg-com_toxic_20161125_sum.pdf (accessed on 23 January 2020).

14. Commission Recommendation 2014/662/EU of 10 September 2014 on Good Practices to Prevent and to Reduce the Presence of Opium Alkaloids in Poppy Seeds and Poppy Seed Products, Brussels, Belgium, Official Journal of the European Union, L 271/96 2014. Available online: https:/ / eur-lex.europa.eu/legal-content/EN/TXT/PDF/?uri=CELEX:32014H0662\&from=SK (accessed on 23 January 2020).

15. European Food Safety Authority. Update of the Scientific Opinion on opium alkaloids in poppy seeds, EFSA Panel on Contaminants in the Food Chain (CONTAM). EFSA J. 2018, 16, 5243. [CrossRef]

16. Thevis, M.; Opfermann, G.; Schänzer, W. Urinary concentrations of morphine and codeine after consumption of poppy seeds. J. Anal. Toxicol. 2003, 27, 53-56. [CrossRef]

17. Acevska, J.; Dimitrovska, A.; Stefkov, G.; Brezovska, K.; Karapandzova, M.; Kulevanova, S. Development and validation of a reversed-phase HPLC method for determination of alkaloids from Papaver somniferum L. (Papaveraceae). J. AOAC Int. 2012, 95, 399-405. [CrossRef]

18. Cao, Q.; Li, S.; He, C.; Li, K.; Liu, F. Extraction and determination of papaverin in pericarpium papaveris using aqueous two-phase system of poly(ethyleneglycol)-(NH4)2SO4 coupled with high-performance liquid chromatography. Anal. Chim. Acta 2007, 590, 187-194. [CrossRef]

19. Guo, Q.Z.; Zhang, J.; Zhao, S.; Shao, B. Determination of five alkaloids of pericarpium papaveris in hot pot broth using ultraperformance liquid chromatography coupled to triple quadruple mass spectrometry. Food Anal. Methods 2013, 6, 698-704. [CrossRef]

20. Stranska, I.; Skalicky, M.; Novak, J.; Matyasova, E.; Hejnák, V. Analysis of selected poppy (Papaver somniferum L.) cultivars: Pharmaceutically important alkaloids. Ind. Crop. Prod. 2013, 41, 120-126. [CrossRef]

21. Casado, N.; Gañán, J.; Morante-Zarcero, S.; Sierra, I. New advanced materials and sorbent-based microextraction techniques as strategies in sample preparation to improve the determination of natural toxins in food samples. Molecules 2020, $25,702$. [CrossRef]

22. Xu, F.; Liu, F.; Wang, C.; Wei, Y. Amantadine-functionalized magnetic microspheres and stable isotope labeled internal standards for reducing matrix effect in determination of five opium alkaloids by liquid chromatography-quadrupole linear ion trap mass spectrometry. J. Chin. Chem. Soc. 2019, 66, 484-492. [CrossRef]

23. Tang, T.; Cao, S.; Xi, C.; Li, X.; Zhang, L.; Wang, G.; Chen, Z. Chitosan functionalized magnetic graphene oxide nanocomposite for the sensitive and effective determination of alkaloids in hotpot. Int. J. Biol. Macromol. 2020, 146, 343-352. [CrossRef] [PubMed]

24. Capriotti, A.L.; Cavaliere, C.; LA Barbera, G.; Montone, C.M.; Piovesana, S.; Laganà, A. Recent Applications of Magnetic Solid-phase Extraction for Sample Preparation. Chromatographia 2019, 82, 1251-1274. [CrossRef]

25. Tajik, M.; Yamini, Y.; Baheri, T.; Safari, M.; Asiabi, H. Supercritical fluid extraction of papaverine and noscapine from poppy capsules followed by preconcentration with magnetic nano Fe3O4@Cu@diphenylthiocarbazone particles. New J. Chem. 2017, 41, 7028-7037. [CrossRef]

26. Deng, Y.; Qi, D.; Deng, C.; Zhang, A.X.; Zhao, D. Superparamagnetic high-magnetization microspheres with an Fe3O4@SiO2 core and perpendicularly aligned mesoporous $\mathrm{SiO}_{2}$ shell for removal of microcystins. J. Am. Chem. Soc. 2008, 130, 28-29. [CrossRef] [PubMed] 
27. Xu, F.; Liu, F.; Wang, C.; Wei, Y. Reversed-phase/weak anion Exchange magnetic mesoporous microspheres for removal of matrix effects in lipophilic marine biotoxins analysis by ultrahigh-performance liquid chromatography coupled to tandem mass spectrometry. Food Chem. 2019, 294, 104-111. [CrossRef]

28. Zhang, H.-F.; Shi, Y.-P. Magnetic retrieval of chitosan: Extraction of bioactive constituents from green tea beverage samples. Analyst 2011, 137, 910-916. [CrossRef]

29. Zeng, H.; Wang, Y.; Nie, C.; Kong, J.; Liu, X. Preparation of magnetic molecularly imprinted polymers for separating rutin from Chinese medicinal plants. Analyst 2012, 137, 2503-2512. [CrossRef]

30. Lagergren, S. About the theory of so-called adsorption of soluble substances. K. Sven. Vetenskapsakad. Handl. 1898, $24,1-39$.

31. Ho, Y.; McKay, G. Pseudo-second order model for sorption processes. Process. Biochem. 1999, 34, 451-465. [CrossRef]

32. Weber, W.J.; Morris, J.C. Kinetics of adsorption on carbon from solution. J. San. Eng. Div. 1963, 89, 31-60. [CrossRef]

33. Langmuir, I. The adsorption of gases on plane surfaces of glass, mica and platinum. J. Am. Chem. Soc. 1918, 40, 1361-1403. [CrossRef]

34. Freundlich, H.M.F. Over the adsorption in solution. Am. J. Phys. Chem. 1906, 57, 385-471.

35. European Commission SANTE/11813/2017. Guidance Document on Analytical Quality Control and Method Validation Procedures for Pesticide Residues and Analysis in Food and Feed. 2017. Available online: https://www.eurl-pesticides.eu/ userfiles/file/EurlALL/AqcGuidance_SANTE_2019_12682.pdf (accessed on 9 April 2021).

36. Commission Regulation (EC) No 401/2006. Laying Down the Methods of Sampling and Analysis for the Official Control of the Levels of Mycotoxins in Foodstuffs. 2006. Available online: https:/ / eur-lex.europa.eu/legal-content/EN/TXT/PDF/?uri= CELEX:32006R0401\&from=ES (accessed on 9 April 2021).

37. Chen, F.F.; Xie, X.Y.; Shi, Y.P. Preparation of magnetic imprinted polymer for selective recognition of resveratrol in wine. J. Chromatogr. A 2013, 1300, 112-118. [CrossRef]

38. Zhang, M.; Mei, J.; Lv, S.; Lai, J.; Zheng, X.; Yang, J.; Cui, S. Simultaneous extraction of permethrin diastereomers and deltamethrin in environmental water samples based on aperture regulated magnetic mesoporous silica. New J. Chem. 2020, 44, 16152-16162. [CrossRef]

39. Sing, K.S.W.; Everett, D.H.; Haul, R.A.W.; Moscou, L.; Pierotti, R.A.; Rouquérol, J.; Siemieniewska, T. Reporting physisorption data for gas/solid systems with special reference to the determination of Surface area and porosity. IUPAC Pure Appl. Chem. 1984, 57, 603-619. [CrossRef]

40. Cassella, G.; Wu, A.; Shaw, B.; Hill, D. The analysis of thebaine in urine for the detection of poppy seed consumption. J. Anal. Toxicol. 1997, 21, 376-383. [CrossRef] [PubMed]

41. Acevska, J.; Stefkov, G.; Petkovska, R.; Kulevanova, S.; Dimitrovska, A. Chemometric approach for development, optimization, and validation of different chromatographic methods for separation of opium alkaloids. Anal. Bioanal. Chem. 2012, 403, 1117-1129. [CrossRef]

42. Skopikova, M.; Hashimoto, M.; Richomme, P.; Schinkovitz, A. Matrix free laser desorption ionization mass spectrometry as an efficient tool for the rapid detection of opiates in crude extracts of Papaver somniferum. J. Agric. Food Chem. 2020, 68, 884-891. [CrossRef] [PubMed]

43. Zentai, A.; Sali, J.; Szeitznè-Szabó, M.; Szabó, I.; Ambrus, A. Exposure of consumers to morphine from poppy seeds in Hungary. Food Addit. Contam. Part A 2011, 29, 1-12. [CrossRef]

44. Carlin, M.G.; Dean, J.R.; Ames, J.M. Opium alkaloids in harvested and thermally processed poppy seeds. Front. Chem. 2020, 8, 737. [CrossRef]

45. Bjerver, K.; Jonsson, J.; Nilsson, A.; Schuberth, J.; Schuberth, J. Morphine intake from poppy seed food. J. Pharm. Pharmacol. 2011, 34, 798-801. [CrossRef]

46. Hayes, L.W.; Krasselt, W.G.; A Mueggler, P. Concentrations of morphine and codeine in serum and urine after ingestion of poppy seeds. Clin. Chem. 1987, 33, 806-808. [CrossRef] 